\title{
Concentration in Mortgage Markets: \\ GSE Exposure and Risk-Taking in Uncertain Times
}

\section{Ronel Elul}

Federal Reserve Bank of Philadelphia Research Department

\section{Deeksha Gupta}

Carnegie Mellon University and

Visiting Scholar, Federal Reserve Bank of Philadelphia Research Department

\section{David Musto}

University of Pennsylvania and

Visiting Scholar, Federal Reserve Bank of Philadelphia Research Department

ISSN: $1962-5361$

Disclaimer: This Philadelphia Fed working paper represents preliminary research that is being circulated for discussion purposes. The views expressed in these papers are solely those of the authors and do not necessarily reflect the views of the Federal Reserve Bank of Philadelphia or the Federal Reserve System. Any errors or omissions are the responsibility of the authors. Philadelphia Fed working papers are free to download at: https://philadelphiafed.org/researchand-data/publications/working-papers.
|ND20-ก/

PUBLISHED

January 2020

REVISED

January 2022

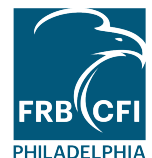




\title{
Concentration in Mortgage Markets: GSE Exposure and Risk-Taking in Uncertain Times
}

\author{
Ronel Elul, Deeksha Gupta, and David Musto*
}

January 14, 2022

\begin{abstract}
When home prices threaten to decline, large mortgage investors can benefit from fostering new lending that boosts demand. We ask whether this benefit contributed to the growth in acquisitions of risky mortgages by the Government Sponsored Enterprises (GSEs) in the first half of 2007. We find that it helps explain the variation of this growth across regions. The growth predicted by this benefit is on top of the acquisition growth caused by the exit of private-label securitizers. We conclude that the GSEs actively targeted their acquisitions to counter home-price declines.
\end{abstract}

Keywords: GSEs, Concentration, Risk Exposure

JEL Classifications: G01, G21, L25, R31.

*Ronel Elul (ronel.elul@phil.frb.org) is at the Federal Reserve Bank of Philadelphia. Deeksha Gupta (deekshagupta@cmu.edu) is at Carnegie Mellon University. David Musto (musto@wharton.upenn.edu) is at the University of Pennsylvania. We would like to thank Anthony DeFusco, Mariassunta Gianetti, Pedro Gete, Daniel Greenwald, Paul Goldsmith-Pinkham, Sonia Gilbukh, Vincent Glode, Itay Goldstein, Christian Opp, Benjamin Keys, Michael Reher, Stijn Van Nieuwerburgh, Albert Zevelev and seminar participants at Baruch College, the Notre Dame Housing Symposium, SFS Cavalcade and American Finance Association meetings for helpful comments. We also thank Kiran Rebholtz for invaluable research assistance. The views expressed in this paper are those of the authors and do not necessarily reflect those of the Federal Reserve Bank of Philadelphia or the Federal Reserve System. This paper is available at www.philadelphiafed.org/researchand-data/publications/working-papers. 


\section{Introduction}

In the first half of 2007 (2007H1), as the default risk of existing mortgages grew from small to large, Fannie Mae and Freddie Mac (the GSEs) grew their acquisition of new mortgages with a focus on riskier mortgages. This acquisition growth occurred at a time when other mortgage market participants, such as private-label securitizers, were shunning riskier mortgages. The mortgages purchased by the GSEs generally fared badly and contributed to the distress of both the GSEs and homeowners when the crisis hit. So why did the GSEs buy them? Did they just passively drift into owning them, and then get unlucky? In this paper, we ask whether the purchases instead served an active strategy to counter a house price drop that would hurt the GSEs' outstanding portfolios of mortgages. We find that this strategy helps explain why the purchases varied as they did across regions. This explanatory power is on top of the passive increase in GSE acquisitions due to the exit of private-label securitizers at this time.

Not only did the GSEs increase their purchase of riskier mortgages significantly in 2007H1, with their high-LTV acquisitions growing by $57 \%$, but they did so much more in some places than others. We find growth of almost $600 \%$ in some MSAs and shrinkage of up to $33 \%$ in others. One possible explanation for both the increase and the variation in the GSEs' purchases in 2007H1 is that they happened passively when the GSEs' competition left the field. If the GSEs had just carried their 2006 acquisition campaigns forward through 2007, they might have drifted into more and riskier mortgages because private-label securitizers, which tended to specialize in riskier products, shrank and exited the mortgage market at the same time, and where the private-label securitizers shrank more, the GSEs would grow more. But that's not what happened: we find that the areas in which the GSEs' acquisitions grew more were generally different from the areas in which private-label securitizers shrank more. The correlation is zero or negative. Moreover, a passive, drifting explanation for the growth we observe runs counter to the GSEs' statements at the time that they were tracking and adapting to the changing circumstances, including the departing securitizers, and it also 
discounts the GSEs' incentive to counter a home-price drop with their market power.

As Gupta (2021) illustrates, lenders with enough scale and credit-risk exposure can gain from pushing out loans when a home-price drop threatens. The extra loans counter the drop by supporting prices, whether by enabling purchases or by forestalling sales with refinancings, and this benefits the lenders by reducing defaults among the existing mortgages whose credit risk they bear. ${ }^{1}$ This benefit would mean little to a small participant, since the likely effect of a few new mortgages on house prices would be minimal. But to a sufficiently large participant the benefit may be high enough to be a strategic consideration. The GSEs are the largest participants in the US mortgage market, and while they do not originate mortgages, they buy mortgages from those who do and then bear their credit risk by either holding or insuring them. Consequently, their acquisition strategies shape the incentives of originators, and they stand to benefit from the effect of expanded originations on their existing loans. Since the GSEs' usual risk boundaries are already well-known to lenders and others, expansion would likely come from outside those boundaries, i.e. from high-risk loans.

The first piece of evidence that this price-support strategy played a role in the GSEs' risky acquisitions is the timing: the GSEs grew these acquisitions when the benefit from supporting prices was at its highest, i.e. when the likelihood of a price drop was both big enough and not too big to fight. The theoretical analysis of Gupta (2021) finds the strongest incentive at the transition out of a housing boom, as these are moments when lenders have substantial outstanding exposures from the boom and when the default risk of those large exposures starts to grow. Evidence that the first months of 2007 were such a moment includes both the paths of default swap spreads on asset-backed securities as well as the GSEs' own statements in statutory filings and elsewhere. ${ }^{2}$ That the growth occurred at the predicted moment supports the price-support explanation but it is not a well-identified test, so for identification we turn to the cross sections of both the benefit and the growth.

\footnotetext{
${ }^{1}$ For convenience we discuss the effect of extra mortgages in terms of demand, though technically the effect of a refinancing mortgage that helps a borrower keep a house she would otherwise have to sell is less supply.

${ }^{2}$ See Stanton and Wallace (2010) and Section 3.2.
} 
The identification comes from the cross sections of the GSEs' regional concentration and of the elasticity of housing supply, as measured by Saiz (2010). The GSEs' regional concentration tells us where they benefit more from price support, and the elasticity of housing supply tells us where the GSEs get more price support per unit of demand support. Elasticity is particularly relevant to managing the end of a boom, considering the larger supply of houses that the boom fosters in higher-elasticity regions, and how much harder this makes it to support their prices when the boom ends. If the GSEs grow their risky acquisitions to mitigate their risk exposures through price support, they should focus this growth where their concentration is high and elasticity is low.

The empirical question is thus a triple difference: is the growth in the GSEs' high-LTV acquisitions greater 1) in 2007H1, 2) where the GSEs are more concentrated, and 3) where elasticity is low? We run this test by tracking regional lending from 2005 to 2008, controlling for regional fixed effects, and the results bear out the price-support hypothesis. There was more growth in 2007H1 where the GSEs were more concentrated, and even more so where elasticity was lower. At the point estimate, in an MSA with an elasticity of 1, i.e. the cusp between inelastic and elastic, a percentage point increase in market share delivers a 0.23 percentage point increase in the proportion of high-LTV mortgages purchased by the GSEs in 2007H1. This relationship between the growth in the GSEs' high-LTV purchases and the cross sections of concentration and elasticity is specific to the $2007 \mathrm{H} 1$ period.

The evidence on strategic targeting leaves open the question of how the GSEs targeted their purchases strategically, and in particular, how to square the discretion implied by strategic targeting with the GSEs' reputation for automated purchases within well-known boundaries. To address this question we focus on the contrast in GSE purchases across the well-known boundary at a 620 FICO score. This boundary divides a region on the right (mortgages with FICO scores above 620) with more automated purchasing from one on the left (mortgages with FICO scores below 620) with more discretionary purchasing. ${ }^{3}$ Below

\footnotetext{
${ }^{3}$ See Keys, Mukherjee, Seru, and Vig (2010).
} 
620 the GSEs could exercise greater discretion through the regional standards of high-profile campaigns such as Home Possible (Freddie) and MyCommunityMortgage (Fannie), and also through ad-hoc community outreach. ${ }^{4}$ We exploit the jump in the role of discretion in a GSE's purchases when the FICO crosses 620 to help us identify greater discretionary growth in the GSEs' risky lending.

We identify the jump with a Regression Discontinuity Design (RDD) model which tests whether the difference between the GSEs' acquisition growth just below vs. just above a FICO of 620 is greater when and where the GSEs benefit more from price support, i.e. in 2007H1, where they are more concentrated, and where housing supply is more inelastic. An added virtue of this test design is that it removes any remaining influence of differences across MSAs by focusing on differences within MSAs among similar loans. The test finds a significant role for discretionary lending: at the point estimates, assuming an elasticity of 1 , the effect on growth in $2007 \mathrm{H} 1$ of a one percentage point increase in concentration is five times bigger just below 620 than it is just above.

Strategic growth in acquisitions does not exclude the possibility of passive growth. The GSEs could have passively filled the voids left by exiting private securitizers while also actively targeting regions for price support. We account for this possibility with a passive model of GSE acquisitions in which their acquisition patterns carry forward from one quarter to the next. Adding this passive model to the regression shows us both what passive drift explains on its own and also whether the active strategy is still significant in its presence. The functional form of the passive model allows the GSEs' acquisitions in a time and place to depend on both their own previous acquisitions there and on the change in acquisitions by private-label securitizers from the previous period, and it further allows the relation to this change to be different in $2007 \mathrm{H} 1$. We additionally allow for a stronger passive relation where the GSEs are more concentrated, to account for the possibility that a stronger connection between the GSEs and local lenders correlates concentration with passive growth. We build

\footnotetext{
${ }^{4}$ We discuss the GSEs' discretionary acquisition channels in greater detail in Section 3.3.
} 
this passive model into both the OLS and RDD tests and find that it does explain significant cross-sectional variance on its own, but the predictions of the active price-support strategy add explanatory power and remain significant.

The evidence for price support is robust to other adjustments. We take a different angle on the passive explanation by testing whether the mortgages retained by the lenders in a region, as opposed to the mortgages sold to the GSEs, display the same relation to the GSEs' outstanding share and supply elasticity in 2007H1. This would be the case if the evidence for price support by the GSEs were instead somehow caused by the lenders for their own reasons. The test comes in negative so this does not explain our results. Also, since each GSEs' motivation to support prices comes primarily from its own exposure, we repeat the regressions with Fannie's acquisitions explained only by Fannie's concentration and Freddie's explained only by Freddie's concentration. The price-support hypothesis still comes in significantly. We further run a falsification test explaining Fannie's growth with Freddie's share and vice versa, and there is no predictive power. We also test whether the growth in high-risk acquisitions can be explained by the agencies' housing goals, as opposed to their incentives to support prices, and find no support for this channel.

The risk we document is quite different from the risks usually associated with concentration, and at first glance it might not even look like a risk. The incentive to take this risk arises from the GSEs' continued exposure to their past borrowers, i.e. from their credit risk retention. While risk retention is generally seen as a good thing (and even encouraged by recent regulation), our paper demonstrates its downside. A favorable view of the dynamic we document is that the GSEs are only helping people buy and refinance, which is their primary mission, in an attempt to keep existing mortgages out of default and foreclosure, which are bad for the economy. But the GSEs' concentration means that this help can take the form of additional risky lending, which increases the fragility of both the new borrowers and the economy as a whole. From a macroprudential perspective, a dynamic that increases fragility may be unappealing, and the risk it poses may be even higher now than it was in 2007. The 
COVID-19 pandemic saw the GSEs increase their market share dramatically in the second half of 2020, which could strengthen their incentives to support prices, while also serving as an instrument of government policy by offering forbearances and avoiding foreclosures. So the possible benefit to the GSEs of price support is an important potential consideration for their post-conservatorship future.

The rest of this paper is arranged as follows. Section 2 describes literature related to our paper. Section 3 gives some background on the GSEs' statements around 2007H1, on the general state of the housing market in 2007 and on the GSEs' geographic targeting. Section 4 describes the data. Section 5 describes the main analysis and our results. The last section concludes.

\section{Related Literature}

Many have analyzed aspects of mortgage lending in and around the financial crisis but few studies focus on the first months of 2007 in particular. Our paper is closest to Bhutta and Keys (2021) who document that issuance of private-mortgage insurance (PMI) surged in the beginning of 2007, and also that this issuance increased disproportionately in the GSE market. They show that PMI issuance grew by nearly 50\% in 2007 with more increase in the riskiest neighborhoods of cities that the PMIs considered high-risk. To explain this surge Bhutta and Keys (2021) provide evidence in support of the moral hazard that can encourage PMI providers to incur excessive future liabilities in exchange for current premiums. This sort of incentive might have also affected the GSEs, i.e. the incentive to buy mortgages with bad future prospects to get their current payments, but that would not vary with concentration and elasticity like the incentive we address here.

There is also a literature on the GSEs' size and structure, and how they may affect the mortgage market. This literature primarily highlights the potential downsides to their implicit government guarantee. The analysis by Jeske, Krueger, and Mitman (2013) calculates a negative net effect of the guarantee on overall welfare, with a worse incidence on lower- 
income consumers, and Elenev, Landvoigt, and Van Nieuwerburgh (2016) connect the implicit guarantee to greater financial fragility (see Acharya, Richardson, Van Nieuwerburgh, and White (2011) for a longer discussion of the role of the GSEs in the housing boom and bust). Gete and Zecchetto (2018) focus on a different guarantee - the insurance the GSEs provide against mortgage default — and find that it also has large distributional effects, benefiting middle-income homeowners most of all. We complement this literature by highlighting a distortion that can arise from the GSEs' market power.

A growing literature considers how lenders' existing exposures affect their incentives to lend. Bond and Leitner (2015) and Gupta (2021) study this question theoretically and Favara and Giannetti (2017) address it empirically, focusing on the influence of existing exposures on decisions about distressed borrowers. They find that existing exposure drives lenders to refrain from foreclosing where their holdings are more concentrated. Additionally, in an empirical study, Bongaerts, Mazzola, and Wagner (2021) find that low market share can be self-perpetuating in that lenders are less likely to approve new mortgages where they have less share as they face a greater risk of uncoordinated fire sales, and also find that this feedback is strongest when fire sales are more salient.

While the literature does not connect regional exposure to originations, it does find adverse effects of size on originations along other dimensions. Nadauld and Sherlund (2013) show that the five largest broker/dealer banks dominated subprime securitization, and argue that the too-big-to-fail doctrine enlarged their appetite for risk, which in turn pushed lenders to lower their underwriting standards. Similarly, Dell'Ariccia, Igan, and Laeven (2012) argue that the dominance of a few large lenders reduced lending standards by reducing competition. Other work connects lender competition to mortgage interest rates and mortgage interest rates to home prices. Scharfstein and Sunderam (2015) find that reduced competition leads to less sensitivity of the rates homeowners pay to the yields on mortgage-backed securities, and Fuster, Lo, and Willen (2016) associate reduced lender competition with higher rates. 


\section{Background}

In this section we make three points that provide the basis for our analysis. The first is that the GSEs' statements in 2007H1 show them choosing to expand into riskier mortgages. The second is that $2007 \mathrm{H} 1$ was a period of transition for the housing market and, in particular, was a time when mortgage default risk rose from small to significant. The third is that the mechanisms with which the GSEs could foster lending with regionally-targeted incentives were different below versus above a 620 FICO score.

\subsection{Active Expansion into Risky Loans}

The GSEs expanded their loan purchases in 2007-08 while private-label securitizers (PLs) left the market. Two points about this expansion are relevant to our analysis. One is that the GSEs focused their 2007 expansion on higher-risk loans. The second is that the GSEs described themselves as actively choosing the loans they bought, rather than passively filling a void.

The exit by the PLs and expansion by the GSEs is apparent in Figures 1 and 2, which plot semiannual purchase totals for the PLs and the GSEs from 2004H2 to 2008H2. The PL exit started in late 2006, and picked up in 2007H1. The figures break out the PLs' and GSEs' purchases into low and high risk by leverage, i.e. loan-to-value (LTV) less than or equal to the standard limit of less than 80 percent vs. greater than 80 percent. This breakout shows that the GSEs' expansion during the PLs' exit was specifically into the high-leverage market, and was larger than the PLs' exit so that the semiannual sum of the two increases by about 100K from 2006H2 to 2007H1. By contrast, the sum of low-LTV loans drops sharply across 2007, with the semiannual sum dropping by almost $600 \mathrm{~K}$. These figures illustrate that the expansion of the GSEs into high-LTV loans as the PLs left that market accomplishes more than just filling the new void.

Another important dimension of mortgage risk, besides LTV, is credit score. For an analogous comparison along this dimension, Figures 3 and 4 separate the mortgages with 
origination FICOs less than and above 660, commonly used as a dividing line between subprime and prime loans. We see that the GSEs expand their subprime lending in late 2006 and early 2007, though by less than the PLs shrink.

Public statements by executives at Freddie Mac and Fannie Mae confirm that the GSEs actively expanded into high-risk mortgages, rather than passively absorbed order flow left behind by the exiting PLs. Freddie Mac's executive vice president of investments commented at Lehman's Annual Financial Services Conference in May 2007:

Today, the subprime market is experiencing maybe capital outflows... we're looking at the subprime market both as an opportunity to generate returns, but also as an opportunity to create some stability and leadership there and provide a way to continue. ${ }^{5}$

Similarly, in a February 2007 investor/analyst conference call, Fannie Mae's executive vice president and chief risk officer stated:

In our filing today, we also indicate that we have increased our participation in subprime product in 2006. Our purchases have been prudent and have been made when we concluded that they would contribute to our mission objectives or they would generate a profitable return. ${ }^{6}$

To summarize, the GSEs' expansion in 2007 focused on higher-risk loans, especially those with high LTV, and the GSEs described themselves as actively choosing, rather than passively accepting, the loans they bought.

\subsection{Risk of a Large Home-Price Drop Grew from Small to Large in 2007H1}

There are several ways to see that the risk of a home-price drop, as perceived by market participants in general and by the GSEs in particular, grew from small to large in 2007H1.

\footnotetext{
5 "Freddie Mac at Lehman Brothers' 10th Annual Financial Services Conference," Fair Disclosure Wire (2007).

6 "Fannie Mae Investor/Analyst Conference Call - Final," Fair Disclosure Wire, February 27th, 2007.
} 
The growth perceived by market participants in general is apparent in CDS spreads and prices, and in other macro statistics. The growth perceived by the GSEs in particular is apparent in the evolution of their statutory filings and public statements over time.

\subsubsection{Risk perceived by market participants in general}

As Stanton and Wallace (2010) and others note, the ABX-HE indices track the market's perception of home-price risk, to the extent it threatens mortgage repayment. These indices cover the spreads and prices of asset-backed securities by vintage and by original ratings. The 2006 vintages were the most sensitive to home-price declines since the equity in those loans did not have the benefit of the earlier price rise. The figures in Stanton and Wallace (2010) show that the 2006 vintages had low spreads and prices near par entering 2007, and then soon saw their spreads rise and prices drop. The more junior tranches saw the biggest losses, such that the BBB and AA tranches lost half their value in 2007H1. Other tranches followed qualitatively similar paths. Market prices thus show mortgage risk growing from small to large in $2007 \mathrm{H} 1$.

This trend is also supported by other statistics. From January to March 2007 housing starts fell 33\%. In March of 2007, New Century Financial saw its stock price fall by half and The Economist reported that investors were "shunning subprime and all mortgages that seemed risky." 7

\subsubsection{Risk perceived by the GSEs in particular}

The perception by the GSEs in particular is tracked by their statutory filings and public statements. Fannie Mae registered its common stock with the SEC before 2006 and thus made statutory filings throughout the period. Freddie Mac did not register until July 2008, so we cannot track its perceptions in 2006-7 through statutory filings, but it did prepare Annual Information Statements in lieu of annual reports, and its leadership commented to

\footnotetext{
7 "Cracks in the Facade," The Economist, 22 March 2007.
} 
the press.

A document review of Fannie Mae's filings finds that the first reference to a potential home-price decline occurred on December 6, 2006, when Fannie filed its 2004 annual report. That filing states, "We expect that growth in total U.S. residential mortgage debt outstanding will continue at a slower pace in 2007, as the housing market continues to cool and home price gains moderate further or possibly decline modestly." ${ }^{8}$ By contrast, the $12 \mathrm{~b}-25$ (i.e. a substitute for the quarterly report that Fannie Mae could not timely file) for 2006Q2 allowed only that home price appreciation may be flat: "We anticipate that the flattening of the yield curve, slower or flat appreciation in home prices, and the payment shock that certain consumers will experience from the reset of many ARMs to higher rates may fuel a further shift into fixed-rate mortgages and longer-term ARMs during the latter half of 2006 and in subsequent years." 9 The analogous filing for 2006Q3 did not report any expectations for home prices. $^{10}$

Fannie Mae's filings through 2007 acknowledge the end of the house-price boom and the growing possibility of a transition to a bust. On February 27th, 2007, in the 12b-25 for FY 2006, Fannie Mae refers to its "belief that home prices are likely to decline in 2007," ${ }^{11}$ and similarly, in the May 2nd filing of its 2005 annual report, it states that "average home prices could go down in 2007,"12 and in its May 9th 12b-25 for 2007Q1, it reports "our belief that home prices could decline modestly in 200\%." ${ }^{13}$ By the time Fannie Mae filed its 2006 annual report on August 16th, declining prices were an accepted fact: "we believe average home prices are likely to continue to decline in 200\%." ${ }^{14}$ So, judging from its official statements, Fannie Mae started to see a possibility of a home-price drop in December 2006, and this

\footnotetext{
${ }^{8}$ Fannie Mae 10-K form for year ended 12/31/04, filed 12/06/06, p. 70.

${ }^{9}$ Fannie Mae form 12b-25 for quarter ended 6/30/06, filed 8/09/06, p. 10.

${ }^{10}$ Fannie Mae form 12b-25 for quarter ended 9/30/06, filed 11/08/06.

${ }^{11}$ Fannie Mae form 12b-25 for year ended 12/31/06, filed 2/27/07, p. 3.

${ }^{12}$ Fannie Mae form 10-K for year ended 12/31/05, filed 5/02/07, p. 4.

${ }^{13}$ Fannie Mae form 12b-25 for quarter ended 3/31/07, filed 5/09/07, p. 3.

${ }^{14}$ Fannie Mae form 10-K for year ended 12/31/06, filed 8/16/07, p. 3.
} 
possibility increased to a certainty by August.

The expectations voiced in Fannie Mae's statutory filings align with the expectations voiced elsewhere. In December 2006, Fannie Mae's chief economist put the chance of a recession at 35 percent, ${ }^{15}$ and in January 2007, put the end of the home-price downturn at mid-year. ${ }^{16}$ At mid-year he pushed off the end of the downturn to the year-end. ${ }^{17}$

Freddie Mac's Annual Information Statements shed less light on its expectations for price declines but are generally consistent. The statement for 2006, dated March 23rd, 2007, reports that Freddie Mac expects home-price appreciation to slow or weaken, but does not address the potential for price declines. The statement for 2007, dated February 28th, 2008, allows that home prices had declined.

Public reports help clarify the path of Freddie Mac's expectations. On January 1st, 2007, National Mortgage News reported that "Freddie Mac's economists are forecasting that house price appreciation in the first half of 2007 will be $3.4 \%$ - about the rate of inflation," 18 and on March 25th, Freddie Mac's chief economist was quoted along the same lines, projecting zero real home-price growth in 2007. ${ }^{19}$ But on June 8th, 2007, after Freddie Mac's repeat-sales index showed home values growing at a $1.3 \%$ annual rate in $\mathrm{Q} 1$, he said "... as the housing market settles near the bottom of its cycle during the second half of this year, we will likely see national home price growth slow further with price declines in many parts of the U.S." 20 Subsequently, on June 28th, he said "This week we saw further effects of the current housing recession." 21 Thus we conclude that the risk of large house-price decline, as perceived by both

\footnotetext{
${ }^{15}$ New York Times, December 26th, 2006, "An Economy of Extremes," by Eduardo Porter, p. C1.

${ }^{16}$ South Florida Sun-Sentinel, January 8th, 2007, "Analysts Take Look at Crystal Ball for 2007," by Robyn Friedman, p.11.

${ }^{17}$ Transcript of Nightly Business Report, Global Broadcast Database - English, June 25th, 2007.

${ }^{18}$ National Mortgage News 31(14), January 1, 2007, "Outlook 2007: Economist Expecting Big Home Price Drop," p. 7.

${ }^{19}$ South China Morning Post, March 25th, 2007, "Will the US Mortgage Crisis Engulf Asia?" by Jacob Leibenluft, p.18.

${ }^{20}$ Investors Business Daily, June 8th, 2007, "House Prices Rising or Falling? Depends on Whom You Ask," by Paul Katzeff, p. A08.

${ }^{21}$ CNNMoney.com, June 28th, 2007, 11:04AM, "Mortgage Rates Back Off Again."
} 
Fannie Mae and Freddie Mac, grew from small to large during $2007 \mathrm{H} 1$.

2007H1 was therefore a pivotal moment for house prices and mortgage risk, as the risk of a drop grew from small to large. This transition identifies these months as the period when the incentive to combat the risk was strongest, as motivated theoretically in Gupta (2021).

\subsection{The GSEs' Strategic Implementation below vs above a 620 FICO}

The GSEs purchase loans both inside and outside well-known credit boundaries, and while some regional targeting is possible within the boundaries, more is possible outside. The bulk of purchases within the boundaries are automatic, and it is hard for the GSEs to influence whether those loans get made since the potential borrowers can easily find out that their loans would have the desirable feature that the GSEs would buy them. The GSEs can still adjust their criteria or the prices they pay for different products, and these changes could

have regional consequences, so there is some ability to target within the boundaries but likely not much. Outside the boundaries, however, potential borrowers could as easily believe that the GSEs would not buy their loans, and on that basis not borrow unless the GSEs or their customers tell them otherwise. So the GSEs have more influence on lending outside their boundaries, and they do this with both nationwide campaigns and narrower initiatives.

We focus on the boundary at a 620 FICO because it is well-known and has been closely studied (Bubb and Kaufman, 2014; Keys et al., 2010). The GSEs elevated the direct importance of 620 by setting it as the line between automatic approval to the right and manual approval to the left, and the literature documents a steep drop in originations below it. But while it is the stated boundary of automatic approval, the GSEs have episodically extended automatic approval below 620, and importantly these extensions can be regionspecific. Going into 2007H1, both GSEs had long-running campaigns targeted at riskier borrowers, Home Possible at Freddie Mac and MyCommunityMortgage at Fannie Mae, which moved boundaries for circumstances and regions at the GSEs' discretion. The GSEs both had automated underwriting systems - Desktop Underwriter for Fannie Mae and Loan 
Prospector for Freddie Mac - that would implement these changes as soon as they were uploaded. Fannie Mae also provided Property Geocoder to show whether a property was in a qualifying region for a program. ${ }^{22}$ An important example of a regionally-targeted change came in January, 2007 when Fannie Mae told lenders it was raising the upper income boundary for MyCommunityMortgage loans in regions from Boston to Hawaii with high median home prices. ${ }^{23}$ The strong response of loan volume to this change is documented below in Section 5.4 .

The GSEs also marketed the news of changes in eligibility requirements to newly-eligible borrowers. One channel this news ran through was strategic partnerships with local lenders and associated professionals. A representative example is Fannie Mae's 2002 campaign to expand lending to lower-income borrowers in Louisiana and Texas. The campaign announcement reports that "The $\$ 5$ billion commitment includes an aggressive menu of affordable-housing mortgage products, a focused product and sales-education program for the origination team, outreach and education to real-estate professionals and increased or redeployed resources to previously underserved areas." ${ }^{24}$ Similarly, when Freddie Mac rolled out its Home Possible suite of low down-payment mortgage products in 2005, US Banker reported that Freddie Mac's sales team was "doing dozens and dozens of on-site training sessions and webcasts." 25 Freddie Mac also marketed these mortgages through partnerships with local credit unions, providing them "assistance and training" with "Home Possible Mortgage suite, and other low down payment mortgages designed to help low- and moderate-income borrowers." 26

Besides targeting through automated underwriting by judiciously moving the boundaries and marketing regionally, the GSEs could also target through manual underwriting of the

\footnotetext{
${ }^{22}$ See, e.g., Origination News 10(3), December 2000, "Fannie Uses Geocoder for Property Verification," p. 32 .

${ }^{23}$ Fannie Mae Announcement 07-01, January 23rd, 2007.

${ }^{24}$ Business Wire, March 22nd, 2002, "Hibernia National Bank and Fannie Mae Announce \$5 Billion Affordable-Mortgage Lending Initiative."

${ }^{25}$ US Banker 155(7), July 2005, "Hey (Freddie) Mac, Can You Spare a Mortgage?" by Michael Sisk, p. 44.

26 "Credit Unions Have More Ways to Succeed in Mortgage Lending Business," PR Newswire (2007).
} 
applications outside the boundaries. Lenders exercise discretion over these applications, following the GSEs' advice, so the GSEs could target a region through manual underwriting by targeting this advice.

In summary, the GSEs could target regions more effectively below a 620 FICO than above, so all else equal we should see more loan growth driven by price support below a FICO score of 620 than above. This is the basis of our RDD analysis.

\section{Data and Summary Statistics}

We use loan-level data from Black Knight McDash (henceforth referred to as McDash). These data have been used widely, including to study the determinants of mortgage default (Elul 2016) and the expansion of credit during the housing boom (Adelino, Schoar, and Severino 2016). These data are provided by the servicers of the loans, and the contributors include the majority of the top servicers. We focus on first mortgages that are originated or outstanding starting from 2005, since coverage of the McDash data was not as extensive prior to that date (particularly for subprime loans), and continuing through 2008.

The McDash data cover about two-thirds of all mortgage originations in these years. We restrict attention to owner-occupied homes and exclude multifamily properties. The McDash data set is divided into a "static" file, with values that do not change over time, and a "dynamic" file. The static data set contains information obtained at the time of the original underwriting, such as the loan amount at origination, house value at the origination date and origination FICO score. The dynamic file is updated monthly. The most important dynamic variables for our analysis are the current principal balance and the investor type: private-securitized, Fannie Mae, Freddie Mac, portfolio, FHA. ${ }^{27}$ Because of the time it takes a loan to go through the securitization pipeline, many mortgages are initially recorded as portfolio loans when they first appear in the data set; therefore, we define the "investor type at origination" to be that reported at six months from loan origination. In addition, in

\footnotetext{
${ }^{27}$ Our FHA investor type includes FHA and VA loans, as well as other loans in GNMA securities.
} 
some of our tests we also use loan-level data from the public Home Mortgage Disclosure Act (HMDA) data set to calculate the share of GSE goals-eligible loans. Finally, we merge in MSA-level housing supply measures from Saiz (2010). The elasticity measures vary between 0 and 12 with a higher number indicating a more elastic MSA.

Table 1 summarizes the experience of the average MSA in 2007H1. The GSEs increased their purchases of high-LTV mortgages by $57 \%$ on average across MSAs while the PLs decreased theirs by 50\%. There is wide variation around these means, which we present graphically in Figure 5, which shows the dispersion across MSAs of the GSEs' growth, and Figure 6, which shows the dispersion of the PLs' retreat. The patterns do not tell a purely passive story in which one is simply the opposite of the other. In fact, the GSE growth and the PL retreat show a slight negative correlation of -.06 .

Our empirical tests gain their identification from the time series and from the variation across MSAs of the GSEs' outstanding shares and of housing supply elasticity. Both of these quantities vary substantially across MSAs, as can be seen in Figure 7, which plots the variation of the GSEs' share of non-jumbo loans in 2007H1 and shows a range from $22 \%$ to 88\%, and Figure 8 which plots the elasticities. According to Saiz (2010), land-constrained cities have elasticities at or below one, and the plot shows a large number of MSAs on either side of one.

\section{Empirical Analysis}

In this section we test whether the GSEs targeted their purchases of riskier mortgages in 2007H1 to support their existing portfolios. We refer to this targeting as the strategic model. The tests use both the time series and the cross section of regions, and are in four groups. In the first group, we test whether the GSEs increased their riskier purchases more in 2007H1 where they were more concentrated, and especially where home-price elasticity was low. In the second group, we run an RDD to test whether the growth of GSE purchases was higher below vs above a $620 \mathrm{FICO}$, when and where the GSEs benefited from price support. In 
the third group, a passive model competes with the strategic model to explain the GSEs' purchases. Finally, we provide direct evidence of the GSEs' ability to geographically target acquisitions, run robustness checks and address alternative hypotheses. We control for region fixed effects in all our tests to absorb any time invariant differences across MSAs.

\subsection{Explaining the Change in High-Risk Purchases}

The first group of regressions explains regional changes in the incidence of high-risk mortgages among the GSEs' purchases. We begin by explaining the changes with the GSEs' regional concentration, testing Hypothesis 1:

Hypothesis 1. The incidence of high-risk mortgages among the GSEs' purchases increased more in 2007H1 where the GSEs were more concentrated.

To test this hypothesis, we first calculate the proportion of high risk mortgages, i.e. LTV $>80 \%$, among GSE purchases in each region $i$ and period $t$, which we denote $H R I_{i, t}$. We use LTV as a key determinant of mortgage risk because of the salience of a potential house price decline at this time. We consider FICO scores in the next group of tests when we focus on discretionary purchases.

The dependent variable $\Delta H R I_{i, t}$ is the first difference, i.e. $H R I_{i t}-H R I_{i, t-1}$. The regions are all the MSAs with available data, and the periods are the half-years from 2005 to 2008. The regression model is thus

$$
\Delta H R I_{i, t}=\alpha+\beta_{1} S H R_{i, t}+\beta_{2} 2007 H 1_{t}+\beta_{3} S H R_{i, t} \times 2007 H 1_{t}+\epsilon_{i, t},
$$

where $S H R_{i, t}$ is the GSEs' share of all outstanding mortgages in region $i$ at the beginning of period $t$ and $2007 H 1_{t}$ is an indicator for the first half of 2007 . The hypothesis predicts a positive value for the coefficient $\beta_{3}$ on the interaction term. The results are reported in the first column of Table 2.

The regression finds that the GSEs tilted more toward high-LTV mortgages in 2007H1 in the regions where they were more exposed. This positive relation in 2007H1 contrasts with 
the significantly negative relation between growth and regional exposure in other periods, indicating some amount of mean reversion in the GSEs' high-LTV acquisitions.

The GSEs' purchase patterns line up with their regional exposures as predicted by the strategic model, but other forces might correlate the two. For example, both regional exposures and lending choices in 2007H1 might depend on the size of the GSEs' local networks. So to sharpen the prediction of the strategic model, we interact exposures with home-price elasticity to marry the motive to support prices that arises from high exposure with the opportunity presented by low elasticity, which magnifies the price support resulting from demand support, especially given the high excess housing supply that high-elasticity regions would see after booms.

We use the elasticities estimated by Saiz (2010), which date to the same era and which have been used in several other subsequent studies (Chaney, Sraer, and Thesmar, 2012; Loutskina and Strahan, 2015; Adelino et al., 2016; Chakraborty, Goldstein, and MacKinlay, 2018). A consideration in using these estimates, highlighted by Davidoff (2016), is their potential correlation with unobserved housing demand. In particular, land constraints are key to the estimation, and places like San Francisco and Manhattan are both highly land-constrained and highly desirable for wealthy people to live in. For this critique to apply to our result, given the double differencing, demand to live in land-constrained areas would have to have been higher in early 2007 than at other times, and even more so in areas where the GSEs' concentration was higher. Our test assumes that this contingency, which appears a priori unlikely, does not apply.

We state the prediction as Hypothesis 2:

Hypothesis 2. The relation between the GSEs' concentration and the incidence of high-risk mortgages among their $2007 H 1$ purchases is stronger when home-price elasticity is lower.

The hypothesis test amounts to a triple interaction, 2007H1 interacted with $S H R$ interacted with home-price elasticity. We denote the home-price elasticity from Saiz (2010) 
for region $i$ as $H P E_{i}$ and expand the regression accordingly to

$$
\begin{aligned}
\Delta \mathrm{HRI}_{i, t} & =\alpha+\beta_{1} S H R_{i, t}+\beta_{2} H P E_{i}+\beta_{3} 2007 H 1_{t}+\beta_{4} S H R_{i, t} \times H P E_{i}+\beta_{5} 2007 H 1_{t} \times H P E_{i} \\
& +\beta_{6} 2007 H 1_{t} \times S H R_{i, t}+\beta_{7} 2007 H 1_{t} \times S H R_{i, t} \times H P E_{i}+\epsilon_{i, t} .
\end{aligned}
$$

Hypothesis 2 predicts a negative value for $\beta_{7}$. The results are in the second and third columns of Table 2 .

The triple interaction comes in negative, indicating that elasticity reduces the effect of concentration on the incidence of risky purchases in 2007H1. On its own, a region's elasticity has a positive marginal effect on the GSEs' tilt toward riskier mortgages in 2007H1, but as the GSEs' exposure to the region grows, this effect turns negative. So for illustration, if the GSEs had no existing exposure to the region, the effect of a 1 unit decrease in elasticity would be a $10.8 \%$ decrease in the incidence of risky purchases, but if the GSEs' exposure were $100 \%$, the effect would be a $4 \%$ increase. Our estimates imply that a relatively low elasticity of 1 associates a 1 percentage point increase in the GSEs' outstanding share, with a .23 percentage point increase in the proportion of high-LTV mortgages purchased by the GSEs in the first half of 2007 relative to other periods.

The regression also finds a positive relation to the interaction of $2007 \mathrm{H} 1$ and elasticity. This implies that, absent the effect of concentration, the GSEs scaled back more in more inelastic regions. This aversion to inelastic regions is consistent with the larger boom in such regions documented in Mian and Sufi (2011), in that a larger boom threatens a larger bust.

For a better sense of how 2007H1 departs from the usual experience, we repeat the regression with separate indicators for each half-year, and then plot the time series coefficients on the triple difference. The result is Figure 9, which shows that 2007H1 stands out as the period when higher concentration and lower elasticity teamed up to increase the GSEs' risky acquisitions. 


\subsection{Regression Discontinuity around FICO 620}

In this subsection we run the RDD motivated in Section 3.3. to test for the discretionary component of regional targeting. The empirical question is whether the growth predicted by the price-support hypothesis, i.e. growth in 2007H1 in high-concentration, low-elasticity MSAs, was higher just below vs at or above a FICO score of 620 . Accordingly we define $620^{-}$ as the number of mortgage loans purchased by the GSEs with FICO scores between 610 and 619 , and $620^{+}$as the number of mortgage loans purchased by the GSEs with FICO scores between 620 and 629, and the prediction is Hypothesis 3:

Hypothesis 3. Growth in the GSEs' acquisitions in 2007H1, where their concentration is higher and elasticity is lower, is higher in $620^{-}$than in $620^{+}$.

A virtue of the RDD test is that it addresses any concerns that could arise from identifying from the cross section of MSAs. This is because the RDD adds within-MSA variation, $620^{-}$vs $620^{+}$to the identification. To run the test, we first calculate the growth in GSE acquisitions for each region $i$, period $t$ and loan bucket $k\left(620^{-}\right.$or $\left.620^{+}\right)$as $\Delta 620_{k, i, t}=\frac{620_{k, i, t}-620_{k, i, t-1}}{620_{k, i, t-1}}$.

Before adding the $620^{-}$vs $620^{+}$fourth dimension to the triple difference, we ease interpretation by first running the triple difference regression separately on the $620^{-}$and $620^{+}$ subsamples, with the dependent variable $\Delta H R I_{i, t}$ replaced by $\Delta 620^{-}$and $\Delta 620^{+}$respectively. The results, in Table 3, find significant evidence of strategically targeted price support in the higher-discretion but not lower-discretion region, as indicated by the triple-difference coefficients. So the separate regressions bear out the prediction of a stronger effect with more discretion.

We put the subsamples together for the quadruple-difference test, regressing $\Delta 620_{k, i, t}$ on the GSEs' outstanding share, house price elasticity, the indicator for 2007H1 and the 
indicator $620_{k}^{-}$that is 1 for loans in $620^{-}$. The full regression is thus

$$
\begin{aligned}
\Delta 620_{k, i, t} & =\alpha+\beta_{1} 620_{k}^{-} \times S H R_{i, t} \times 2007 H 1_{t}+\beta_{2} 620_{k}^{-} \times S H R_{i, t} \times H P E_{i} \times 2007 H 1_{t}+\beta_{3} 620_{k}^{-}+\beta_{4} S H R_{i, t} \\
& +\beta_{5} H P E_{i}+\beta_{6} 2007 H 1_{t}+\beta_{7} 620_{k}^{-} \times S H R_{i, t}+\beta_{8} 620_{k}^{-} \times H P E_{i}+\beta_{9} S H R_{i, t} \times H P E_{i}+\beta_{10} S H R_{i, t} \\
& \times H P E_{i} \times 620_{k}^{-}+\beta_{11} 2007 H 1_{t} \times 620_{k}^{-}+\beta_{12} 2007 H 1_{t} \times H P E_{i}+\beta_{13} 2007 H 1_{t} \times S H R_{i, t} \\
& +\beta_{14} 2007 H 1_{t} \times H P E_{i} \times 620_{k}^{-}+\beta_{15} 2007 H 1_{t} \times S H R_{i, t} \times H P E_{i}+\epsilon_{i, t} .
\end{aligned}
$$

The coefficients testing for the effect of concentration on discretionary purchases in 2007H1, and for the effect of concentration combined with low elasticity on discretionary purchases in $2007 \mathrm{H} 1$, are $620^{-} \times S H R \times 2007 H 1$ and $620^{-} \times S H R \times H P E \times 2007 H 1 .^{28}$ Results are in Table 4.

The four-way difference shows that the effect of discretion within MSAs bears out the strategic price-support hypothesis. Both the effect of concentration and the effect of the combination of concentration and low elasticity on 2007H1 loan growth are significantly stronger among the loans that allow more discretion. At the point estimates, assuming an elasticity of 1 , the effect on $2007 \mathrm{H} 1$ growth of a one percentage point increase in concentration is about five times bigger below a FICO score of 620 than it is above.

To compare $2007 \mathrm{H} 1$ to other periods we run the same exercise from Figure 9 for the triple-difference and quadruple-difference tests, with separate indicators for each half-year. The results, in Figures 10 and 11, show that the effect of discretion on the effect of the combination of high concentration and low elasticity is specific to $2007 \mathrm{H} 1$.

\section{3. $\quad$ Testing Against a Passive Model}

Firms as large as the GSEs may adapt slowly, and such sluggishness could have drawn the GSEs' strategies for 2006 into 2007. If the GSEs had not adapted at all, they would likely

\footnotetext{
${ }^{28}$ Note that as before, there is no prediction for the effect of low elasticity when it is not combined with concentration, which is what is estimated by $620^{-} \times H P E \times 2007 H 1$.
} 
have purchased more mortgages anyhow due to reduced competition from exiting PLs. We account for this possibility by adding a simple and general passive model to the regression so we can test for the explanatory power of the strategic model net of the passive model.

The passive model allows the GSEs' purchases in a period and region to depend linearly on both their own previous purchases and on the decline in the PLs' purchases in that region. Since the decline in $2007 \mathrm{H} 1$ is unusual, we allow the effect of that decline to be different. Formally, we denote the purchases at time $t$ in region $i$ by lender type $k \in\{g, p\}$, where $g$ denotes GSEs and $p$ denotes PLs, of mortgages of type $j \in\{h, l\}$, where $h$ denotes high-risk, i.e. $L T V>80 \%$, and $l$ denotes low-risk, as $x_{j, i, t}^{k}$. Therefore the model is

$$
x_{j, i, t}^{g}=f_{g} x_{j, i, t-1}^{g}+f_{p}\left(x_{j, i, t-1}^{p}-x_{j, i, t}^{p}\right)
$$

where $f_{g}$ is the fraction applied to GSE purchases the previous period and $f_{p}$ is the fraction applied to the shortfall in the PLs purchases. With this notation, the incidence of high-risk loans among the GSEs' purchases under a purely passive strategy, i.e. $H R I$, is

$$
\frac{x_{h, i, t}^{g}}{x_{h, i, t}^{g}+x_{l, i, t}^{g}}=f_{g} \frac{x_{h, i, t-1}^{g}}{x_{h, i, t}^{g}+x_{l, i, t}^{g}}+f_{p} \frac{x_{h, i, t-1}^{p}-x_{h, i, t}^{p}}{x_{h, i, t}^{g}+x_{l, i, t}^{g}} .
$$

We refer to the first term on the RHS of the above equation, $\frac{x_{h, i, t-1}^{g}}{x_{h, i, t}^{g}+x_{l, i, t}^{g}}$, as GSEOLD and the second term, $\frac{x_{h, i, t-1}^{p}-x_{h, i, t}^{p}}{x_{h, i, t}^{g}+x_{l, i, t}^{g}}$, as PLEXIT. Using this notation, the passive strategy would therefore imply that

$$
H R I=f_{g} G S E O L D+f_{p} P L E X I T
$$

To test the strategic prediction for $\Delta H R I$ in the presence of this passive model, we denote the first differences of GSEOLD and PLEXIT as $\triangle G S E O L D$ and $\triangle P L E X I T$, and then include them as explanatory variables in the regressions, with an interaction that allows the coefficient on $\triangle$ PLEXIT to be different in $2007 \mathrm{H} 1$. We run the regression first with only 
the passive model predicting $\Delta H R I$, to gauge its explanatory power on its own, and then we add the explanatory variables from Table 2 to test the strategic model against the passive model. The results are in Table 5.

The first column of Table 5 shows that the passive model explains significant variation on its own. The negative coefficient on the lagged value $\triangle G S E O L D$ implies mean reversion in $\triangle H R I$, and the positive coefficient on $2007 H 1$ reflects the overall surge in risky lending then. The coefficients on $\triangle P L E X I T$ and $\triangle P L E X I T \times 2007 H 1$ are not significant, so we do not find a relationship either in general or in $2007 \mathrm{H} 1$ in particular between regional exit by PLs and entry by the GSEs.

The second and third columns of Table 5 show that the strategic model is still significant in the presence of the passive model, with similar coefficients. So the passive model helps explain the GSEs' purchases but the prediction of the strategic model is robust to its inclusion.

We can expand the passive model to allow for another possible dependency, which is that the effect of PL exit on GSE entry might be stronger where the GSEs were already more concentrated, in particular if a large regional lender network underlies both the greater concentration and the additional purchases. To include this possibility we let $f_{p}$ vary with concentration by interacting $\triangle P L E X I T_{i, t}$ with $S H R_{i, t}$. The result, in the last two columns of Table 5, shows that higher GSE concentration, if anything, works against the positive relation between the GSEs and the PLs in 2007H1. It also shows that the strategic model is robust to this possible effect of concentration on loan acquisition in $2007 \mathrm{H} 1$.

Finally we add the passive model to the Table 3 tests for discretionary growth. For this we have to adjust the definitions of PLEXIT and GSEOLD to match the dependent variables, which are specific to the FICO buckets $620^{-}$and $620^{+}$. Accordingly we define PLEXIT as the growth in $x_{k, i, t-1}^{p}-x_{k, i, t}^{p}$, where $k$ is the FICO bucket, and GSEOLD as the growth of GSE acquisitions in FICO bucket $k$. The results of the regressions, in Table 6 , show that the strategic model is still significant with this addition. Thus we conclude that the passive model, while helpful and relevant to GSE purchases, does not account for the significance of 
the strategic model.

\subsection{Direct Evidence of Geographic Targeting, Robustness and Alternative Hypotheses}

The empirical tests find the hallmarks of strategic price support in the expansion of the GSEs' risky acquisitions. These are 1) the expansion coincided with the 2007H1 peak in the benefit to this strategy, 2) the expansion correlated across MSAs with the GSEs' existing exposure, 3) the expansion was even stronger when high exposure combined with low price elasticity, and 4) the expansion was stronger when the GSEs had more discretion. Support for this strategic explanation coexists with the alternative passive explanation for the GSEs risky purchases, i.e. that they drifted into them when the PLs exited. In this subsection we address remaining concerns and consider and test some additional alternate hypotheses. We also provide direct evidence that lending volume responds to geographic targeting.

Did the GSEs cause more lending when they loosened the standards for their purchases? To support prices, the GSEs need to both loosen their standards and get the word out to the lenders and borrowers so that the newly eligible loans actually happen. There are different ways the GSEs can spread the news and they don't all leave a public record. One that does leave a record is published announcements, and on January 23rd, 2007, Fannie Mae Announcement 07-01 reported expanded standards for the MyCommunityMortgage program, which was designed for borrowers with FICOs below 620, where the expansion was higher income limits in selected regions with high median home prices. ${ }^{29}$ Did this expansion lead to more high-risk purchases and more high-risk borrowing? We can find out by tracking mortgage originations in these regions across this announcement, and by sorting these originations along two dimensions: those purchased by the GSEs vs those retained by lenders, and those in $620^{-}$vs those in $620^{+}$. The GSE purchases, in the top panel Figure 12, show a significant

\footnotetext{
${ }^{29}$ The regions are Portland, Vancouver, Beaverton, Seattle, Tacoma, Bellevue, Boston, Cambridge, Quincy, New York City, Northern New Jersey, Long Island, New York's Dutchess, Orange, and Ulster Counties and all of California and Hawaii.
} 
increase in $2007 \mathrm{H} 1$ in $620^{-}$and little change in $620^{+}$, while the retained loans in the bottom panel show little change in both credit-score groups. So riskier lending did increase with the announcement of wider standards, and the GSEs absorbed this increase with their purchases.

Is geographic targeting more granular than the MSA-level in practice? We run our regressions at the MSA level because the price elasticities of Saiz (2010) are available only at the MSA level. The actual geographic targeting could have been more granular such as at a census tract or city level. What is important for the test design is for the subdivisions of an inelastic MSA to be generally less elastic than those of an elastic MSA.

Is our finding due to lenders expanding for their own reasons? Our main tests address this possibility by relating the expansion specifically to the GSEs' incentives, as quantified by the concentrations and elasticities, and by focusing on the GSEs' discretionary purchases by exploiting the contrast across 620 . We can also address this possibility directly by asking whether the loans retained by the lenders follow the same relations as the loans they sell to the GSEs. Accordingly, we repeat the regression explaining the increase in high-risk acquisitions, only with the GSEs' purchases replaced by the lenders' retentions. The results, in Table 7, find no evidence for this alternate hypothesis.

Is our finding due to the GSEs serving their housing goals, rather than supporting their existing holdings? Congress sets housing goals for the GSEs. The GSEs see little consequence from falling short of these goals (Acharya et al. 2011) but the goals could still influence the GSEs' purchases, including in early 2007. We could therefore mistake the influence of the goals for support of existing holdings if changes in the goals correlate across MSAs with the existing holdings. To account for this possibility we repeat the regressions explaining the increase in high-risk purchases, except now the explanatory variables are replaced by the MSA-level change in goals. The results are in Table 8; in columns 1 and 2 the explanatory variable is the change in the number of loans in the MSA that count toward the GSEs' goals, while in columns 3 and 4 the number of eligible loans is multiplied by the average number of goals that a loan in the MSA counts towards. The second regression accounts 
for the possibility of serving several goals with one loan. With or without that adjustment, the change in the goals does not relate significantly to the change in the GSEs' high-LTV purchases. Therefore our finding does not appear to reflect the GSEs' goals.

Do the results hold if each GSE cared only about its own exposure? We can test for this narrower causality by separating Fannie from Freddie. We do this by running one regression where the dependent variable is Fannie's acquisition growth and the explanatory variable $S H R$ is Fannie's share of mortgages in the region, and another regression where the dependent variable is Freddie's acquisition growth and $S H R$ is Freddie's share. The results are in Panel A of Table 9 .

We find that each of the GSEs responds to its own exposure. Fannie's acquisition growth in 2007H1 increases when elasticity is low where Fannie is more concentrated. Similarly, Freddie's acquisition growth in 2007H1 depends on Freddie's exposure. The coefficients interacting the outstanding share with the elasticity in 2007H1, our key variable of interest, are significant across the board.

The results from separating Fannie from Freddie could in principle result from correlation between Fannie and Freddie in their regional acquisition growth and in their concentration. However, we find that the correlation between their concentrations is negative, $-3 \%$, so that is not driving the results. We also run a falsification test, which switches $S H R$ between regressions, so that Fannie's growth is predicted by Freddie's share and vice versa. We do this in Panel B of Table 9, and the results show no predictive power. Our results are therefore specific to each of the GSEs responding to its own concentration.

Were the GSEs just gambling for resurrection? The price-support strategy bears some resemblance to the standard risk-shifting strategy, in which added risk moves value from the bad insolvency state to the good solvency state. The price-support strategy also makes the bad state worse; the economic difference is that it aims to shrink the probability of the bad state, rather than to move its value to the good state. Both strategies are consistent with the GSEs buying more loans where they already had more, in the price-support case because 
it supports prices in the portfolio more, and the risk-shifting case because it undiversifies the portfolio more. But only the price-support strategy ties the new purchases to the combination of concentration and low elasticity. The low elasticity helps defend against the bad state without moving value from the bad state to the good state.

\section{Conclusion}

The GSEs buy a large fraction of the mortgages in the communities they serve, and they also retain the credit risk of most of the mortgages they buy. We ask whether this combination of concentration and risk retention heightens fragility, when a downturn becomes a possibility, by encouraging new purchases that support the value of old ones. In particular, we test whether this incentive pushed the GSEs further into riskier products when a downturn threatened in early 2007, and we find that it did. These strategic acquisitions were on top of the passive acquisition growth due to the GSEs' competitors shrinking and leaving.

Scrutiny of the crisis highlights the role of risk retention, and the usual question is whether market participants retained too little. For the GSEs, low risk retention has never been an issue, since bearing credit risk is fundamental to their role in the market. We ask instead whether their retention may have been too high, or at least, high enough to introduce an incentive that skews their acquisitions. We conclude that this retention-driven incentive amplified the growth of their risky acquisitions in regions that regulators and others can identify in advance, i.e. the regions with particularly high GSE concentration and low home-price elasticity.

The concentration of the GSEs has long raised concerns about the anticompetitive effects of their government backing. The concern raised by our results is not about competition but rather internalization. Because of their concentration, the GSEs internalize more of the externalities of the marginal home purchase, and while this internalization may have positive effects in some scenarios, the effect when a home-price drop threatens is towards higher systemic risk. If the GSEs succeed at their goal then this internalization might appear 
benign or beneficial, but if they fail then the downturn is likely to be worse than it would have been. Our results thus help explain why the Great Recession was as bad as it was, while also allowing for the possibility that other potential downturns were successfully fought off.

The GSEs entered conservatorship after the 2008 fall of Lehman Brothers and they are still there. This governmental oversight may reduce the incentive we document, though not necessarily. The government's incentive to fight off a downturn through mortgage purchases could be even stronger than the incentives of independent GSEs, since the government internalizes the effects of the purchases through more than just the GSEs' portfolios. Indeed, the GSEs' have been increasingly used as an instrument of government policy, offering forbearances and avoiding foreclosures during the pandemic. The government, operating through the GSEs, may be at least as willing to trade a more severe recession, if it happens, for a higher probability of good times. 


\section{References}

Acharya, V. V., M. Richardson, S. Van Nieuwerburgh, and L. J. White (2011). Guaranteed to Fail: Fannie Mae, Freddie Mac and the Debacle of Mortgage Finance. Princeton, NJ: Princeton University Press.

Adelino, M., A. Schoar, and F. Severino (2016). Loan Originations and Defaults in the Mortgage Crisis: The Role of the Middle Class. Review of Financial Studies 29(7), $1635-1670$.

Bhutta, N. and B. J. Keys (2021). Eyes Wide Shut? Mortgage Insurance During the Housing Boom. Review of Financial Studies (forthcoming).

Bond, P. and Y. Leitner (2015). Market run-ups, market freezes, inventories, and leverage. Journal of Financial Economics 115(1), 155-167.

Bongaerts, D., F. Mazzola, and W. Wagner (2021). Fire Sale Risk and Credit. Working Paper.

Bubb, R. and A. Kaufman (2014). Securitization and Moral Hazard: Evidence from Credit Score Cutoff Rules. Journal of Monetary Economics 63, 1-18.

Chakraborty, I., I. Goldstein, and A. MacKinlay (2018). Housing Price Booms and Crowdingout Effects in Bank Lending. Review of Financial Studies 31(7), 2806-2853.

Chaney, T., D. Sraer, and D. Thesmar (2012). The Collateral Channel: How Real Estate Shocks Affect Corporate Investment. American Economic Review 102(6), 2381-2409.

Davidoff, T. (2016). Supply Constraints Are Not Valid Instrumental Variables for Home Prices Because They Are Correlated With Many Demand Factors. Critical Finance Review 5, $177-206$. 
Dell'Ariccia, G., D. Igan, and L. Laeven (2012). Credit Booms and Lending Standards: Evidence from the Subprime Mortgage Market. Journal of Money, Credit and Banking 44 (23), 367-384.

Elenev, V., T. Landvoigt, and S. Van Nieuwerburgh (2016). Phasing out the GSEs. Journal of Monetary Economics 81(C), 111-132.

Elul, R. (2016). Securitization and Mortgage Default. Journal of Financial Services Research 49(2-3), 281-309.

Favara, G. and M. Giannetti (2017). Forced Asset Sales and the Concentration of Outstanding Debt: Evidence from the Mortgage Market. Journal of Finance 72(3), 1081-1118.

Fuster, A., S. H. Lo, and P. S. Willen (2016). The Time-Varying Price of Financial Intermediation in the Mortgage Market. Federal Reserve Bank of New York Staff Report No. 805 .

Gete, P. and F. Zecchetto (2018). Distributional Implications of Government Guarantees in Mortgage Markets. Review of Financial Studies 31(3), 1064-1097.

Gupta, D. (2021). Too Much Skin-in-the-Game? The Effect of Mortgage Market Concentration on Credit and House Prices. Review of Financial Studies (forthcoming).

Jeske, K., D. Krueger, and K. Mitman (2013). Housing, Mortgage Bailout Guarantees and the Macro Economy. Journal of Monetary Economics 60(8), 917-935.

Keys, B. J., T. Mukherjee, A. Seru, and V. Vig (2010). Did Securitization Lead to Lax Screening? Evidence from Subprime Loans. Quarterly Journal of Economics 125(1), $307-362$.

Loutskina, E. and P. E. Strahan (2015). Financial Integration, Housing, and Economic Volatility. Journal of Financial Economics 115(1), 25-41. 
Mian, A. R. and A. Sufi (2011). House Prices, Home Equity-Based Borrowing, and the U.S. Household Leverage Crisis. American Economic Review 101(5), 2132-56.

Nadauld, T. D. and S. M. Sherlund (2013). The Impact of Securitization on the Expansion of Subprime Credit. Journal of Financial Economics 107(2), 454-476.

Saiz, A. (2010). The Geographic Determinants of Housing Supply. Quarterly Journal of Economics 125(3), 1253-1296.

Scharfstein, D. and A. Sunderam (2015). Market Power in Mortgage Lending and the Transmission of Monetary Policy. Working Paper. Available at https://www.hbs.edu/faculty/Pages/item.aspx?num=44239.

Stanton, R. and N. Wallace (2010). CMBS Subordination, Rating Inflation, and the Crisis of 2007-2009. NBER Working Paper Series. 


\section{7. $\quad$ Figures and Tables}

Figure 1: GSEs' and Private-Label High-LTV Purchases

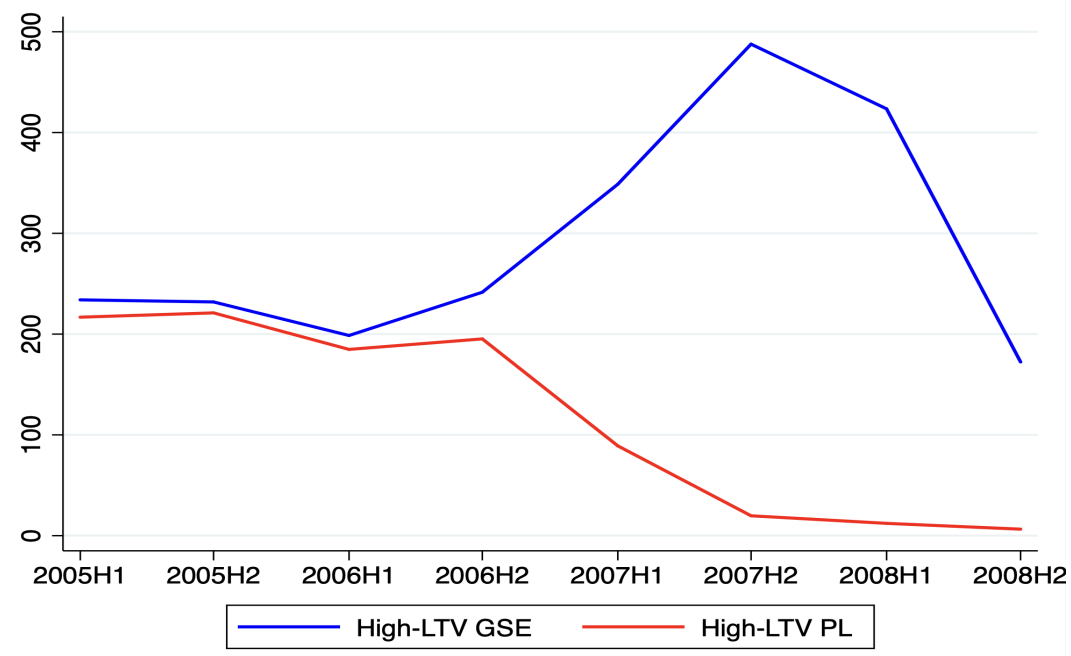

The figure above plots purchases by the GSEs and private-label securitizers from 2004 to 2008. High-LTV refers to loans with LTV $>80$. Y-axis values are in the millions. Data are semi-annual. McDash originations have been scaled to match HMDA totals. Source: McDash.

Figure 2: GSEs' and Private-Label Low-LTV Purchases

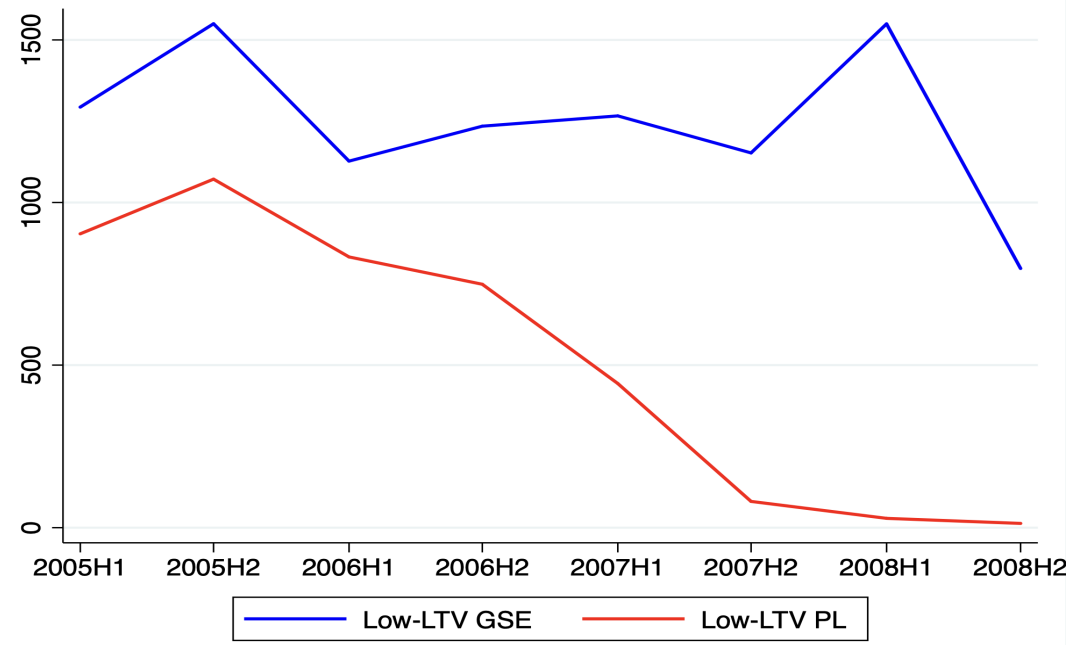

The figure above plots purchases by the GSEs and private-label securitizers from 2004 to 2008. Low-LTV refers to loans with $\mathrm{LTV} \leq 80 . \mathrm{Y}$-axis values are in the millions. Data are semi-annual. McDash originations have been scaled to match HMDA totals. Source: McDash. 
Figure 3: GSEs' and Private-Label Low-FICO Purchases

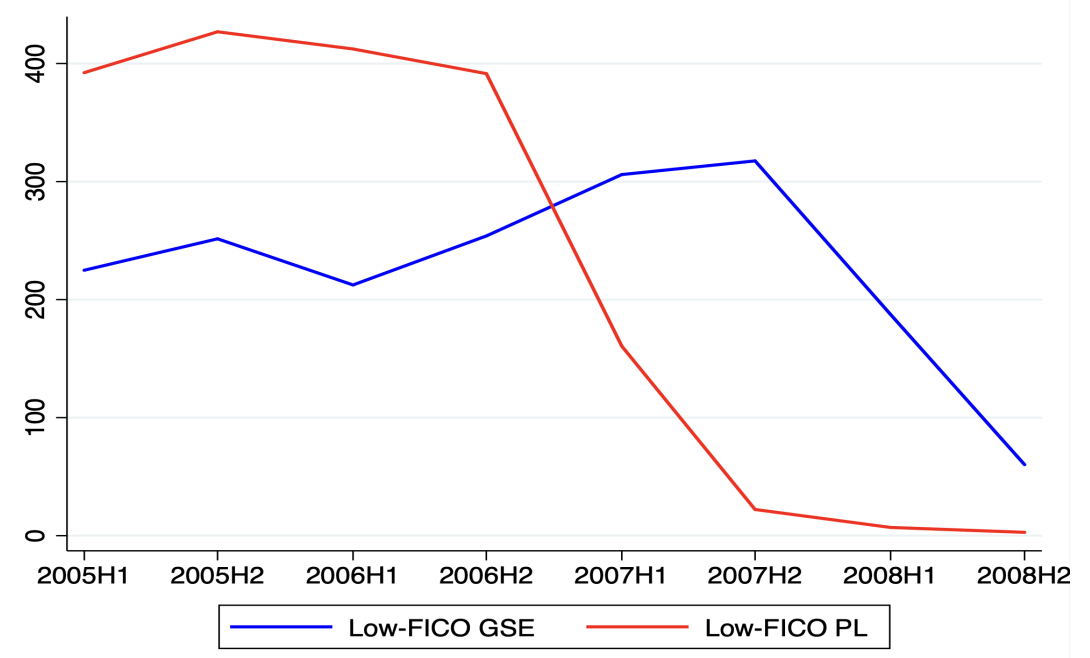

The figure above plots purchases by the GSEs and private-label securitizers from 2004 to 2008. Low-FICO refers to loans with FICO $<660$. Y-axis values are in the millions. Data are semi-annual. McDash originations have been scaled to match HMDA totals. Source: McDash.

Figure 4: GSEs' and Private-Label High-FICO Purchases

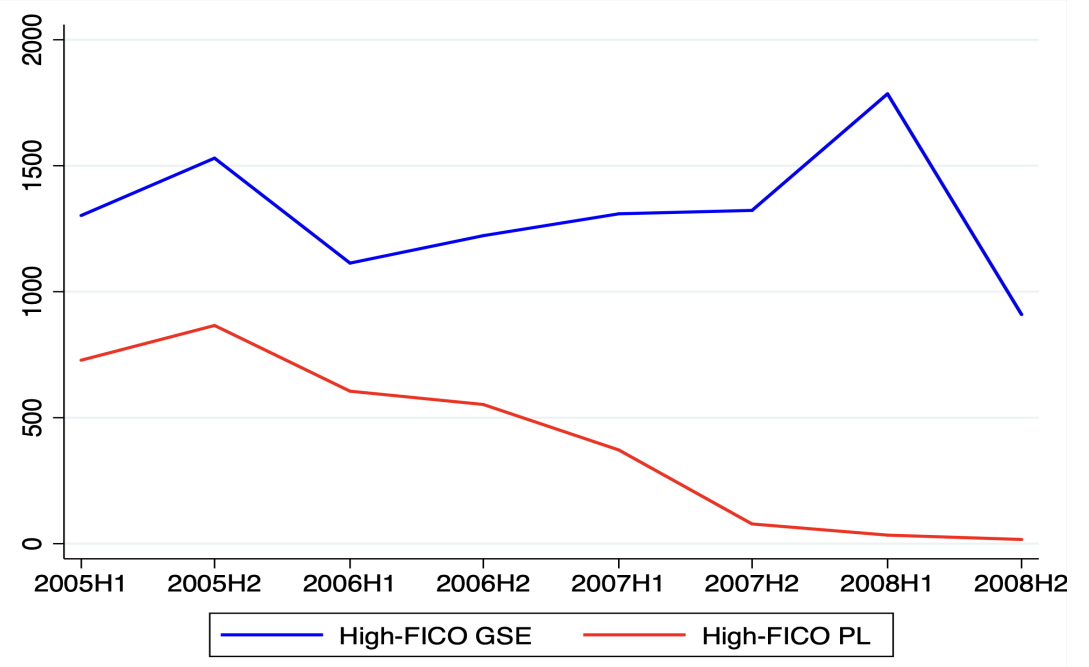

The figure above plots purchases by the GSEs and private-label securitizers from 2004 to 2008. High-FICO refers to loans with $\mathrm{FICO} \geq 660$. Y-axis values are in the millions. Data are semi-annual. McDash originations have been scaled to match HMDA totals. Source: McDash. 
Figure 5: Variation in the GSEs' High-LTV Growth in 2007H1 by MSA

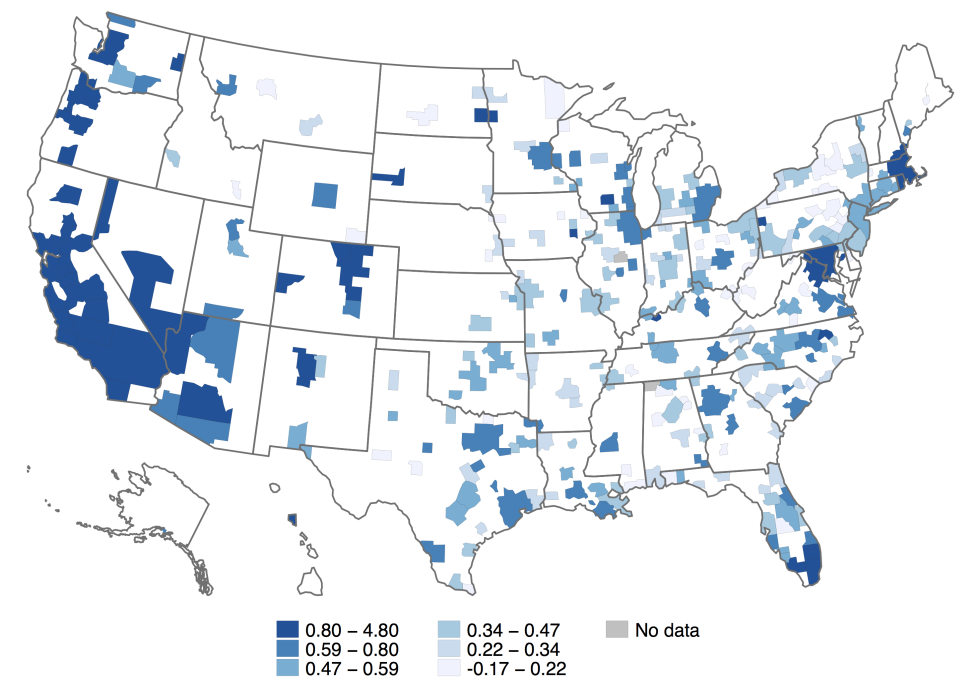

The map above shows the variation in the growth in mortgages purchased by the GSEs that had LTV $>80$ between $2006 \mathrm{H} 2$ and 2007H1. Source: McDash.

Figure 6: Variation in the Private-Label's High-LTV Retreat in 2007H1 by MSA

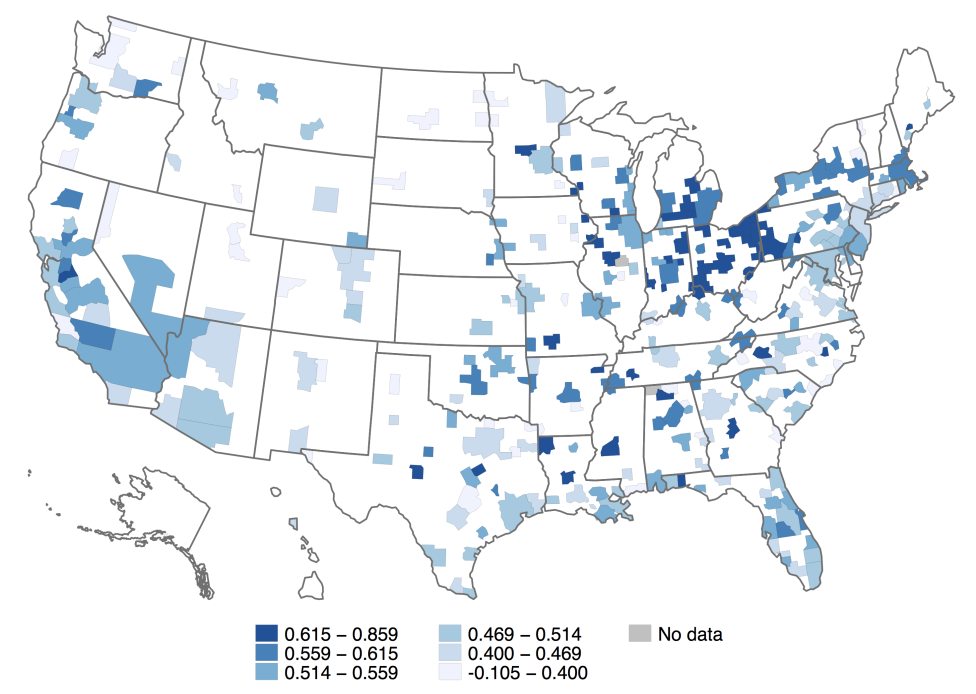

The map above shows the variation in the contraction of mortgages (negative of growth rate) purchased by private-label securitizers that had LTV>80 between 2006H2 and 2007H1. Source: McDash. 
Figure 7: Variation in the GSEs' Outstanding Share at Start of 2007H1 by MSA

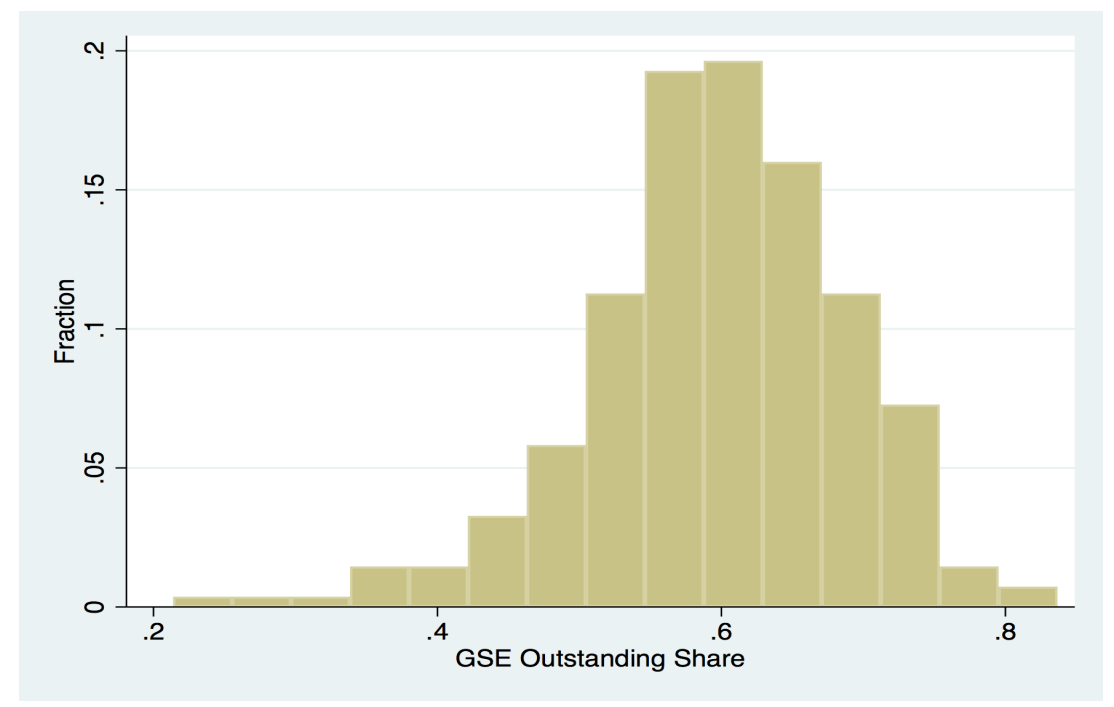

The histogram above shows the variation in the GSEs' outstanding share of non-jumbo mortgages across MSAs at the start of 2007. Source: McDash.

Figure 8: Variation in Housing Supply Elasticities by MSA

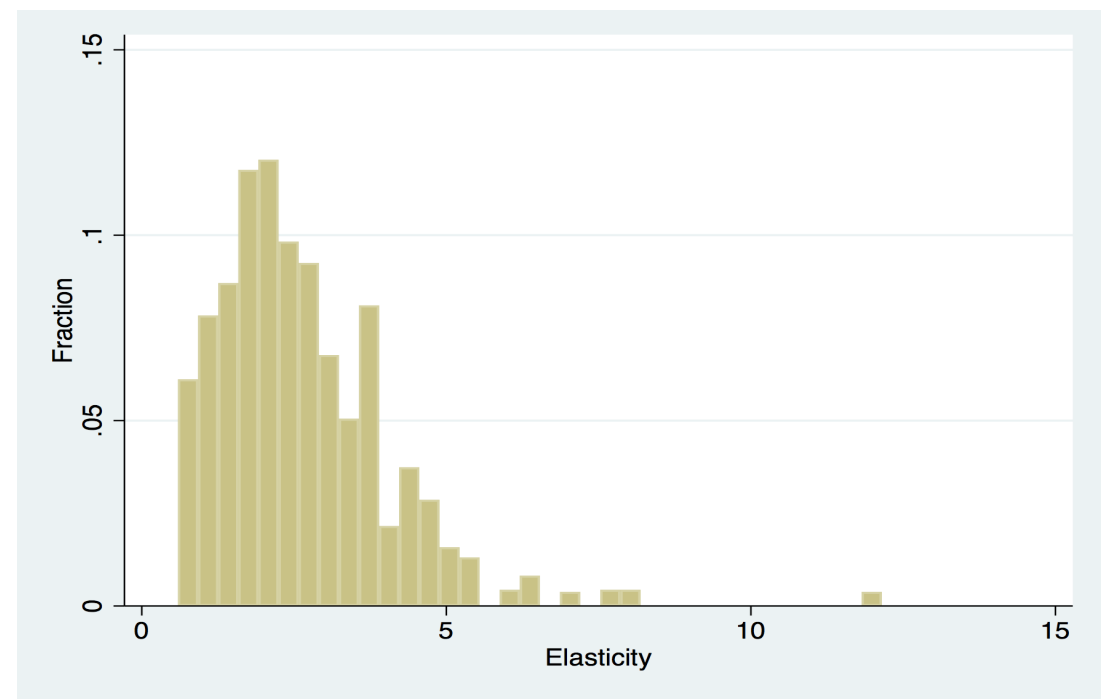

The histogram above shows the variation in housing supply elasticities taken from Saiz (2010). Source: McDash. 
Figure 9: Dynamic Regressions: Change in High-Risk Acquisitions

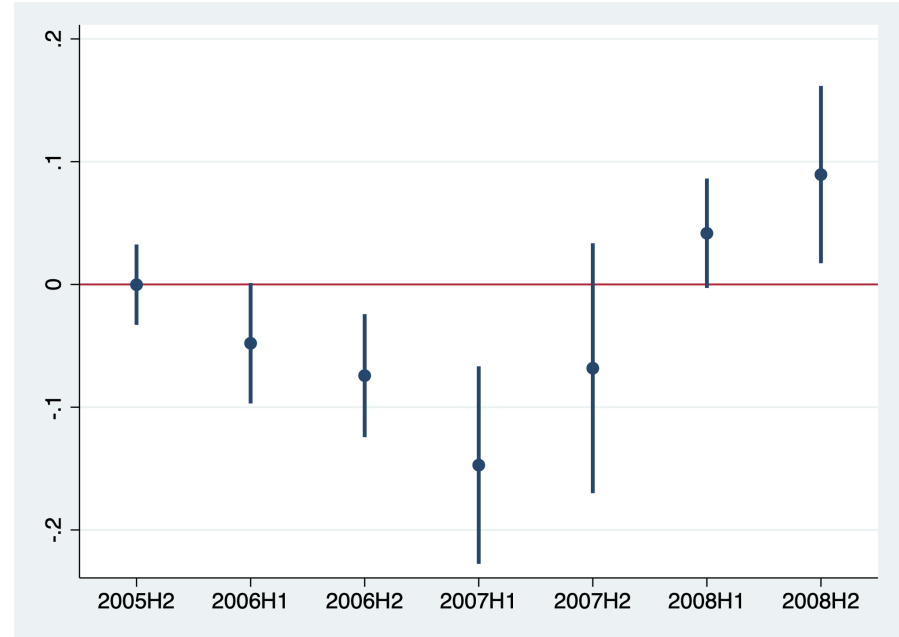

(a) Plot of coefficients on term $\delta_{t} \times S H R i, t * H P E_{i}$

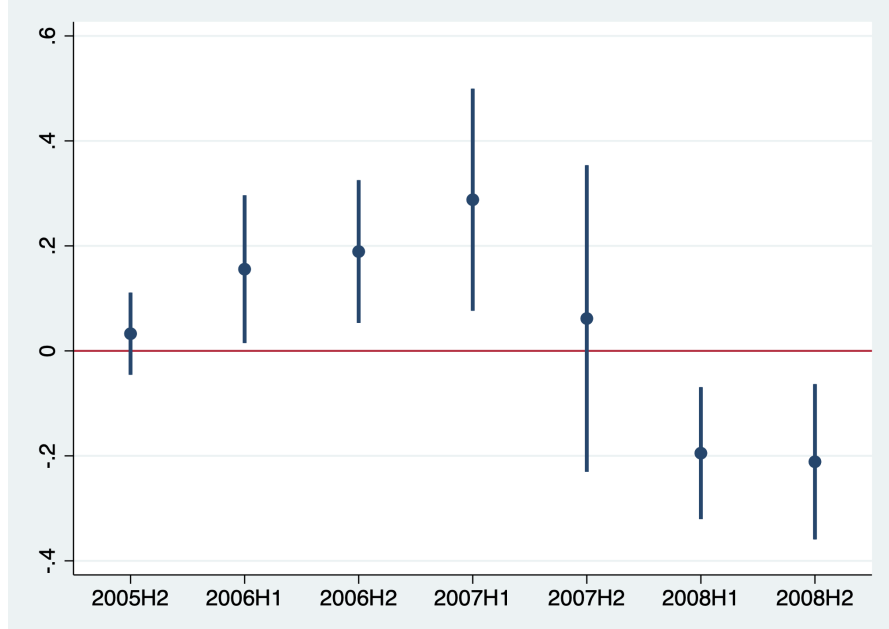

(b) Plot of coefficients on term $\delta_{t} * S H R_{i, t}$

The figures above plot the estimated coefficients of the following regression:

$$
\Delta \mathrm{HRI}_{i, t}=\alpha+S H R_{i, t}+H P E_{i}+S H R_{i, t} * H P E_{i}+\sum_{t} \delta_{t}+\sum_{t} \delta_{t} * S H R_{i, t}+\sum_{t} \delta_{t} * H P E_{i}+\sum_{t} \delta_{t} * S H R_{i, t} * H P E_{i}
$$

$\Delta \mathrm{HRI}_{i, t}$ is the change in the proportion of mortgages purchased by the GSEs that had LTV $>80$ in MSA $i$ at time $t . S H R_{i, t}$ is the GSEs' share of all outstanding mortgages in MSA $i$ at the beginning of time $t . H P E_{i}$ is the Saiz measure of elasticity in MSA $i . \delta_{t}$ is an indicator that takes value 1 at the half year $t$ and is 0 otherwise. The regression includes MSA fixed effects. The panel data are semi-annual and span from 2005 to 2008 . The error bars around the markers represent $95 \%$ confidence intervals around the estimates. Sources: McDash and Saiz (2010). 
Figure 10: Dynamic Regressions: Loan Growth around FICO of 620

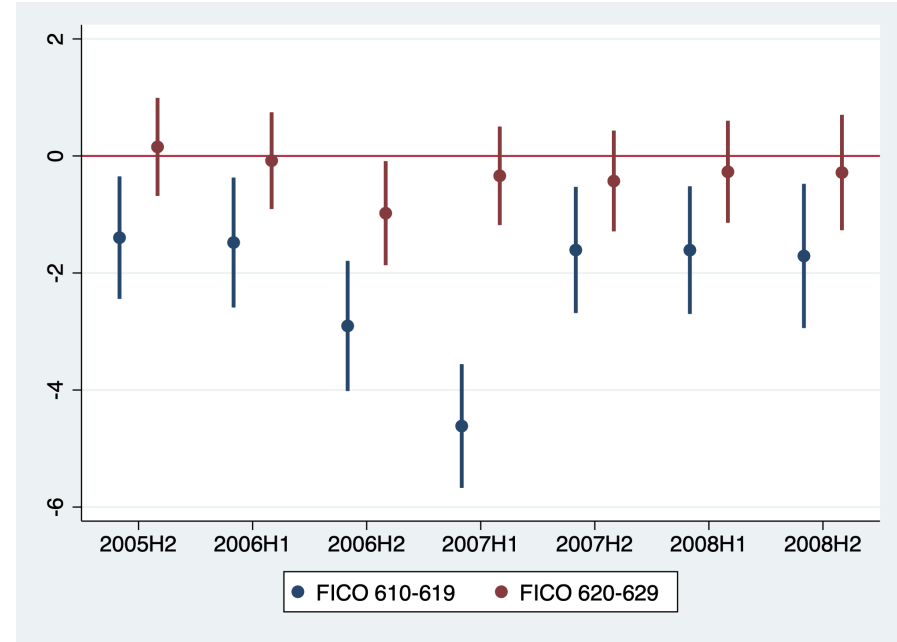

(a) Plot of coefficients on term $\delta_{t} \times S H R_{i, t} \times H P E_{i}$

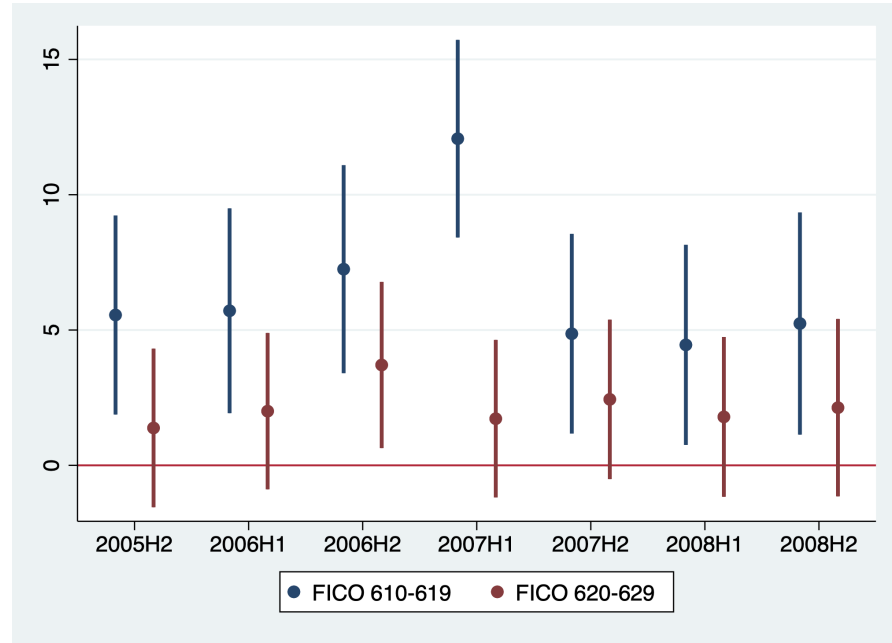

(b) Plot of coefficients on term $\delta_{t} \times S H R_{i, t}$

The figures above plot the estimated coefficients of the following regressions:

$$
\begin{aligned}
\Delta 620_{i, t}^{-/+} & =\alpha+\sum_{t} \delta_{t} S H R_{i, t}+\sum_{t} \delta_{t} H P E_{i}+\sum_{t} \delta_{t}+S H R_{i, t} \times H P E_{i}+\sum_{t} \delta_{t} \times H P E_{i} \\
& +\sum_{t} \delta_{t} \times S H R_{i, t}+\sum_{t} \delta_{t} \times S H R_{i, t} \times H P E_{i}+\epsilon_{i, t}
\end{aligned}
$$

$\Delta 620_{i, t}^{-/+}$is the annual growth in loans purchased by the GSEs which are $620^{-}$(FICO between 610-619) and which are $620^{+}$ (FICO between 620-629) in MSA $i$ at time $t . S H R_{i, t}$ is the GSEs' share of all outstanding mortgages in MSA $i$ at the beginning of time t. HPE $i$ is the Saiz measure of elasticity in MSA $i . \delta_{t}$ is an indicator that takes value 1 at the half year $t$ and is 0 otherwise. The blue coefficients are from the regression of loans that are $620^{-}$while the red coefficients are from the regression of loans that are $620^{+}$. The regression includes MSA fixed effects. The panel data are semi-annual and span from 2005 to 2008. The error bars around the markers represent 95\% confidence intervals around the estimates. Sources: McDash and Saiz (2010). 
Figure 11: Dynamic Regressions: Relative Loan Growth of FICO below 620 to above 620

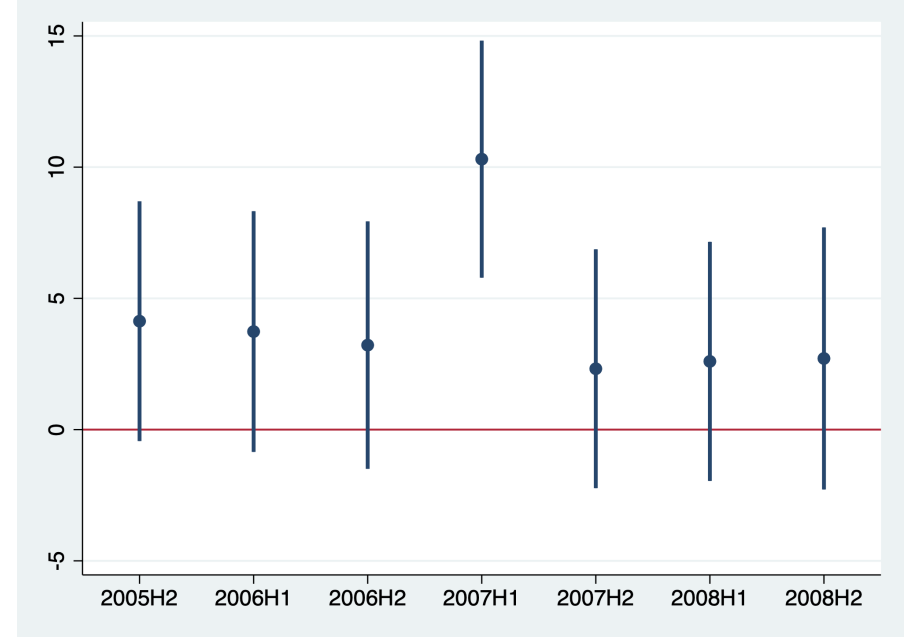

(a) Plot of coefficients on term $\delta_{t} \times S H R_{i, t} \times H P E_{i} \times 620_{k}^{-}$

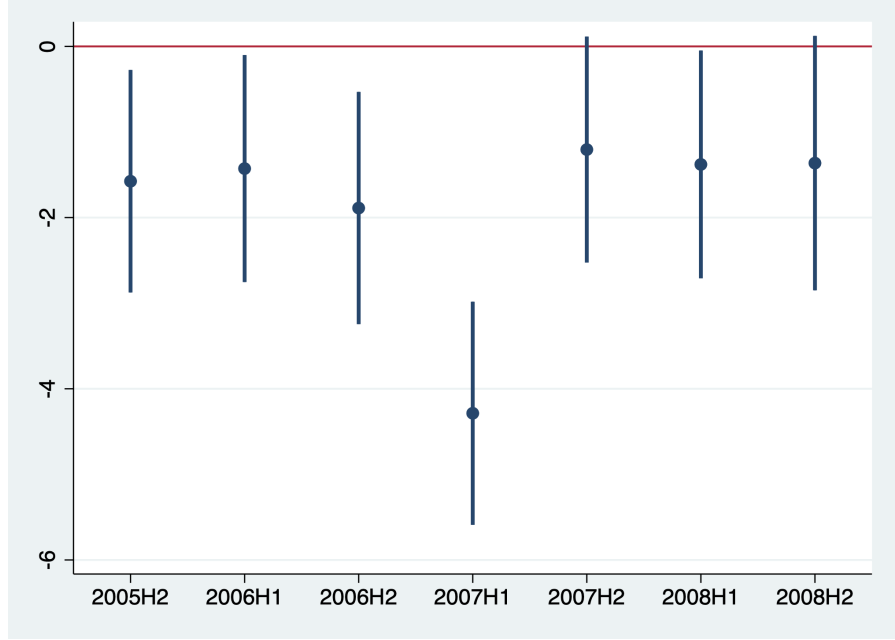

(b) Plot of coefficients on term $\delta_{t} \times S H R_{i, t} \times 620_{k}^{-}$

The figures above plot the estimated coefficients of the following regression:

$$
\begin{aligned}
\Delta 620_{k, i, t} & =\alpha+\sum_{t} \delta_{t} \times S H R_{i, t} \times 620_{k}^{-}+\sum_{t} \delta_{t} \times S H R_{i, t} \times H P E_{i} \times 620_{k}^{-}+620_{k}^{-}+S H R_{i, t}+H P E_{i}+\sum_{t} \delta_{t} \\
& +620_{k}^{-} \times S H R_{i, t}+620_{k}^{-} \times H P E_{i}+S H R_{i, t} \times H P E_{i}+S H R_{i, t} \times H P E_{i} \times 620_{k}^{-}+\sum_{t} \delta_{t} \times 620_{k}^{-} \\
& +\sum_{t} \delta_{t} \times H P E_{i}+\sum_{t} \delta_{t} \times S H R_{i, t}+\sum_{t} \delta_{t} \times H P E_{i} \times 620_{k}^{-}+\sum_{t} \delta_{t} \times S H R_{i, t} \times H P E_{i}+\epsilon_{i, t}
\end{aligned}
$$

$\Delta 620_{k, i, t}$ is the annual growth in loans purchased by the GSEs of type $k 620^{-}$(FICO between 610-619) or 620 ${ }^{+}$(FICO between 620-629) in MSA $i$ at time $t$. $S H R_{i, t}$ is the GSEs' share of all outstanding mortgages in MSA $i$ at the beginning of time $t$. $H P E_{i}$ is the Saiz measure of elasticity in MSA $i .620_{k}^{-}$is an indicator that takes value 1 if $k$ equals $620^{-}$and 0 otherwise. $\delta_{t}$ is an indicator that takes value 1 at the half year $t$ and is 0 otherwise. The regression includes MSA fixed effects. The panel data are semi-annual and span from 2005 to 2008 . The error bars around the markers represent $95 \%$ confidence intervals around the estimates. Sources: McDash and Saiz (2010). 
Figure 12: Relaxation of Community Lending Standards in 2007H1

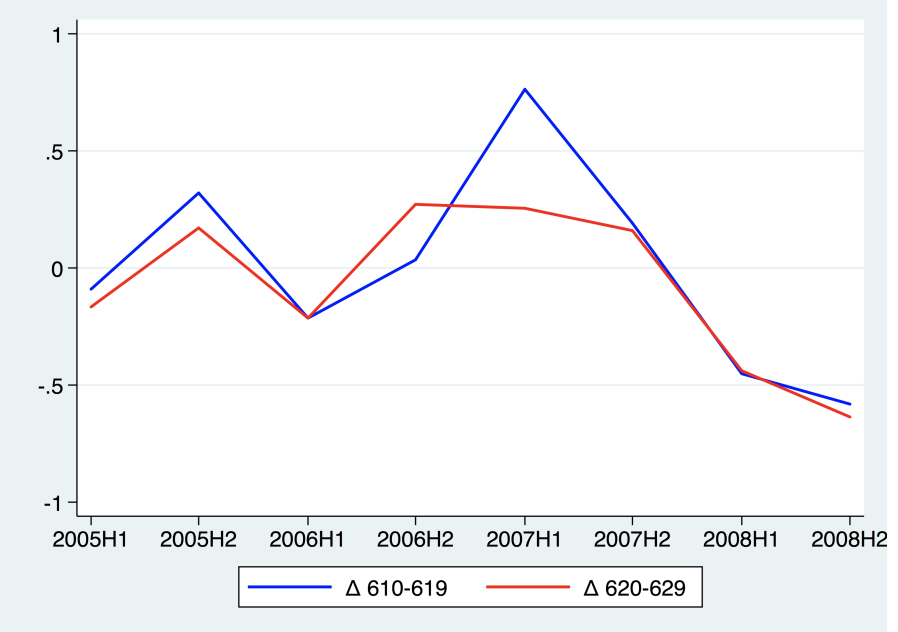

(a) Fannie Mae acquisitions

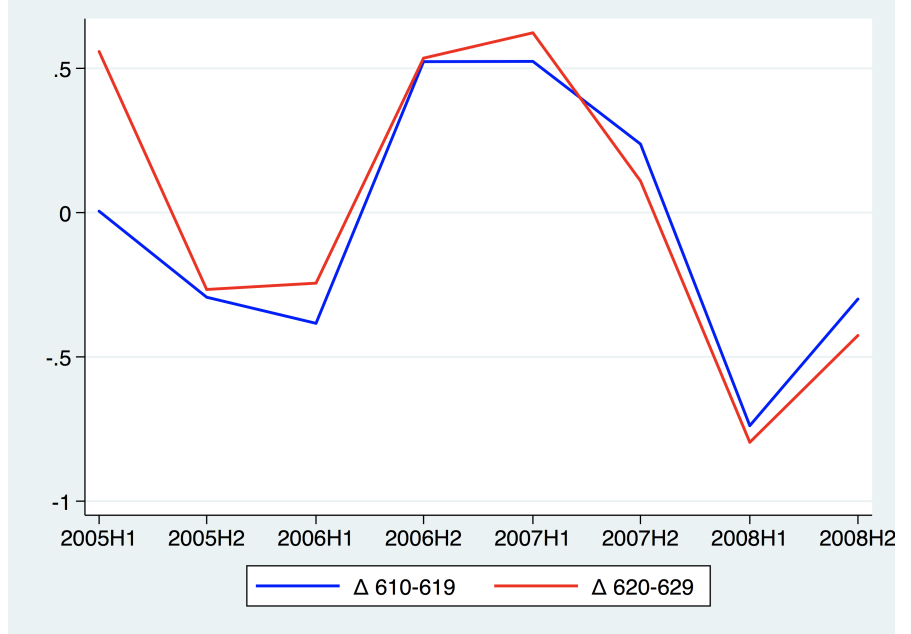

(b) Loans held of portfolio by lenders

The figures above plot loans with FICO scores between 610-619 and between 620-629 in MSAs in which community lending standards were relaxed in 2007 that were acquired by Fannie Mae (top panel) and that were held on portfolio by lenders (bottom panel). Source: McDash. 
Table 1: Summary Statistics — 2007H1

\begin{tabular}{|c|c|c|c|c|}
\hline & \multicolumn{4}{|c|}{ GSEs } \\
\hline & Mean & Standard Deviation & Min & $\operatorname{Max}$ \\
\hline Growth in Number of High-LTV Acquisitions & 0.57 & 0.70 & -0.33 & 6.00 \\
\hline Growth in Number of Low-FICO Acquisitions & 0.25 & 0.28 & -0.52 & 2.67 \\
\hline Growth in Fraction of High-LTV Acquisitions & 0.06 & 0.04 & -0.12 & 0.19 \\
\hline \multirow{3}{*}{ Growth in Fraction of Low-FICO Acquisitions } & 0.02 & 0.04 & -0.18 & 0.18 \\
\hline & \multicolumn{4}{|c|}{ Fannie Mae } \\
\hline & Mean & Standard Deviation & Min & Max \\
\hline Growth in Number of High-LTV Acquisitions & 0.57 & 0.70 & -0.33 & 6.00 \\
\hline Growth in Number of Low-FICO Acquisitions & 0.25 & 0.28 & -0.52 & 2.67 \\
\hline Growth in Fraction of High-LTV Acquisitions & 0.06 & 0.04 & -0.12 & 0.19 \\
\hline \multirow[t]{3}{*}{ Growth in Fraction of Low-FICO Acquisitions } & 0.02 & 0.04 & -0.18 & 0.18 \\
\hline & \multicolumn{4}{|c|}{ Freddie Mac } \\
\hline & Mean & Standard Deviation & Min & Max \\
\hline Growth in Number of High-LTV Acquisitions & 0.78 & 0.76 & -0.28 & 9.00 \\
\hline Growth in Number of Low-FICO Acquisitions & 0.52 & 0.40 & -0.19 & 2.64 \\
\hline Growth in Fraction of High-LTV Acquisitions & 0.06 & 0.05 & -0.14 & 0.28 \\
\hline \multirow[t]{3}{*}{ Growth in Fraction of Low-FICO Acquisitions } & 0.04 & 0.04 & -0.09 & 0.20 \\
\hline & \multicolumn{4}{|c|}{ Private Label } \\
\hline & Mean & Standard Deviation & Min & $\operatorname{Max}$ \\
\hline Growth in Number of High-LTV Acquisitions & -0.50 & 0.14 & -0.86 & 0.11 \\
\hline Growth in Number of Low-FICO Acquisitions & -0.56 & 0.10 & -0.81 & -0.04 \\
\hline Growth in Fraction of High-LTV Acquisitions & -0.02 & 0.06 & -0.30 & 0.21 \\
\hline Growth in Fraction of Low-FICO Acquisitions & -0.08 & 0.07 & -0.45 & 0.11 \\
\hline$N$ & 274 & & & \\
\hline
\end{tabular}

The table reports summary statistics of mortgage activity in the first half of 2007 for the GSEs, Fannie Mae, Freddie Mac, and private-label securitizers. Source: McDash. 


\section{Table 2: Change in High-Risk Acquisitions}

\begin{tabular}{|c|c|c|c|}
\hline & \multicolumn{3}{|c|}{$\Delta$ HRI } \\
\hline & (1) & $(2)$ & (3) \\
\hline SHR $\times 2007 \mathrm{H} 1$ & $\begin{array}{c}0.185^{* * *} \\
(3.17)\end{array}$ & $\begin{array}{c}0.386^{* * *} \\
(5.93)\end{array}$ & $\begin{array}{c}0.377^{* * *} \\
(4.74)\end{array}$ \\
\hline $\mathrm{SHR} \times \mathrm{HPE} \times 2007 \mathrm{H} 1$ & & $\begin{array}{c}-0.133^{* * *} \\
(-5.15)\end{array}$ & $\begin{array}{c}-0.148^{* * *} \\
(-4.53)\end{array}$ \\
\hline $\mathrm{HPE} \times 2007 \mathrm{H} 1$ & & $\begin{array}{c}0.094^{* * *} \\
(5.50)\end{array}$ & $\begin{array}{c}0.108^{* * *} \\
(5.01)\end{array}$ \\
\hline 2007H1 & $\begin{array}{l}-0.053 \\
(-1.39)\end{array}$ & $\begin{array}{c}-0.194^{* * *} \\
(-4.68)\end{array}$ & $\begin{array}{c}-0.204^{* * *} \\
(-4.00)\end{array}$ \\
\hline SHR & $\begin{array}{c}-0.136^{* * *} \\
(-6.33)\end{array}$ & $\begin{array}{c}-0.206^{* * *} \\
(-4.59)\end{array}$ & $\begin{array}{c}-0.791^{* * *} \\
(-4.92)\end{array}$ \\
\hline HPE & & $\begin{array}{c}-0.026 * * * \\
(-2.72)\end{array}$ & \\
\hline $\mathrm{SHR} \times \mathrm{HPE}$ & & $\begin{array}{c}0.041^{* * *} \\
(2.64)\end{array}$ & $\begin{array}{l}-0.048 \\
(-0.73) \\
\end{array}$ \\
\hline MSA FE & $\mathrm{No}$ & No & Yes \\
\hline $\mathrm{R} 2$ & 0.180 & 0.194 & 0.328 \\
\hline $\mathrm{N}$ & 2179 & 1861 & 1861 \\
\hline
\end{tabular}

The table reports the estimated coefficients of the following regression:

$$
\begin{aligned}
\Delta \mathrm{HRI}_{i, t} & =\alpha+\beta_{1} S H R_{i, t}+\beta_{2} H P E_{i}+\beta_{3} 2007 H 1_{t}+\beta_{4} S H R_{i, t} \times H P E_{i}+\beta_{5} 2007 H 1_{t} \times H P E_{i} \\
& +\beta_{6} 2007 H 1_{t} \times S H R_{i, t}+\beta_{7} 2007 H 1_{t} \times S H R_{i, t} \times H P E_{i}+\epsilon_{i, t}
\end{aligned}
$$

$\Delta \mathrm{HRI}_{i, t}$ is the change in the proportion of mortgages purchased by the GSEs that had LTV>80 in MSA $i$ at time $t . S H R_{i, t}$ is the GSEs' share of all outstanding mortgages in MSA $i$ at the beginning of time $t . H P E_{i}$ is the Saiz measure of elasticity in MSA $i .2007 H 1_{t}$ is an indicator that takes value 1 if $t$ equals the first half of 2007. The panel data are semi-annual and span from 2005 to 2008. Standard errors are clustered at the MSA level and are analytically weighted. ***, ${ }^{* *}$, and * indicate significance at the $1 \%, 5 \%$, and $10 \%$ level. T-statistics are shown in brackets. Sources: McDash and Saiz (2010). 
Table 3: Growth in Loans around FICO score of 620

\begin{tabular}{|c|c|c|c|c|}
\hline & \multicolumn{2}{|c|}{$\Delta 620^{-}$} & \multicolumn{2}{|c|}{$\Delta 620^{+}$} \\
\hline & $(1)$ & $(2)$ & $(3)$ & 4 \\
\hline \multirow[t]{2}{*}{$\mathrm{SHR} \times 2007 \mathrm{H} 1$} & $8.827^{* * *}$ & $8.056^{* * *}$ & 1.247 & 0.436 \\
\hline & $(4.05)$ & $(3.55)$ & $(1.37)$ & $(0.42)$ \\
\hline \multirow[t]{2}{*}{$\mathrm{SHR} \times \mathrm{HPE} \times 2007 \mathrm{H} 1$} & $-3.229 * * *$ & $-3.179 * * *$ & -0.235 & -0.152 \\
\hline & $(-4.84)$ & $(-4.44)$ & $(-0.72)$ & $(-0.40)$ \\
\hline \multirow{2}{*}{$\mathrm{HPE} \times 2007 \mathrm{H} 1$} & $2.198^{* * *}$ & $2.201^{* * *}$ & 0.180 & 0.161 \\
\hline & $(4.70)$ & (4.38) & $(0.80)$ & $(0.62)$ \\
\hline \multirow[t]{2}{*}{ 2007H1 } & $-5.194 * * *$ & $-4.828 * * *$ & -0.289 & 0.105 \\
\hline & $(-3.59)$ & $(-3.20)$ & $(-0.48)$ & $(0.15)$ \\
\hline \multirow[t]{2}{*}{ SHR } & $-1.842^{* * *}$ & $-9.475^{* * *}$ & $-1.632^{* * *}$ & $-10.691^{* * *}$ \\
\hline & $(-3.08)$ & $(-4.01)$ & $(-4.68)$ & $(-7.02)$ \\
\hline \multirow[t]{2}{*}{ HPE } & -0.123 & & -0.007 & \\
\hline & $(-0.93)$ & & $(-0.09)$ & \\
\hline \multirow[t]{2}{*}{$\mathrm{SHR} \times \mathrm{HPE}$} & 0.266 & -0.280 & 0.073 & 0.039 \\
\hline & $(1.35)$ & $(-0.34)$ & $(0.65)$ & $(0.07)$ \\
\hline MSA FE & No & Yes & No & Yes \\
\hline $\mathrm{R} 2$ & 0.117 & 0.255 & 0.085 & 0.248 \\
\hline $\mathrm{N}$ & 1843 & 1843 & 1861 & 1861 \\
\hline
\end{tabular}

The table reports the estimated coefficients of the following regression:

$$
\begin{aligned}
\Delta 620_{i, t}^{-/+} & =\alpha+\beta_{1} S H R_{i, t}+\beta_{2} H P E_{i}+\beta_{3} 2007 H 1_{t}+\beta_{4} S H R_{i, t} \times H P E_{i}+\beta_{5} 2007 H 1_{t} \times H P E_{i} \\
& +\beta_{6} 2007 H 1_{t} \times S H R_{i, t}+\beta_{7} 2007 H 1_{t} \times S H R_{i, t} \times H P E_{i}+\epsilon_{i, t}
\end{aligned}
$$

$\Delta 620_{i, t}^{-/+}$is the annual growth in loans purchased by the GSEs which are $620^{-}$(FICO between 610-619) in columns (1) and (2) and which are $620^{+}$(FICO between 620-629) in columns (3) and (4) in MSA $i$ at time $t$. SHR $R_{i, t}$ is the GSEs' share of all outstanding mortgages in MSA $i$ at the beginning of time $t . H P E_{i}$ is the Saiz measure of elasticity in MSA $i .2007 H 1_{t}$ is an indicator that takes value 1 if $t$ equals the first half of 2007. The panel data are semi-annual and span from 2005 to 2008. Standard errors are clustered at the MSA level and are analytically weighted. ***,**, and * indicate significance at the $1 \%$, 5\%, and $10 \%$ level. T-statistics are shown in brackets. Sources: McDash and Saiz (2010). 
Table 4: RDD: Growth in Loans around FICO score of 620

\begin{tabular}{|c|c|c|}
\hline & \multicolumn{2}{|c|}{$\Delta 620^{-}$} \\
\hline & $(1)$ & $(2)$ \\
\hline $620^{-} \times \mathrm{SHR} \times 2007 \mathrm{H} 1$ & $\begin{array}{c}7.580^{* * *} \\
(3.00)\end{array}$ & $\begin{array}{c}7.617^{* * *} \\
(2.91)\end{array}$ \\
\hline $620^{-} \times \mathrm{SHR} \times \mathrm{HPE} \times 2007 \mathrm{H} 1$ & $\begin{array}{c}-2.994^{* * *} \\
(-3.53)\end{array}$ & $\begin{array}{c}-3.008^{* * *} \\
(-3.42)\end{array}$ \\
\hline $620^{-} \times 2007 \mathrm{H} 1$ & $\begin{array}{c}-4.904^{* * *} \\
(-2.83)\end{array}$ & $\begin{array}{c}-4.932^{* * *} \\
(-2.75)\end{array}$ \\
\hline $620^{-} \times \mathrm{HPE} \times 2007 \mathrm{H} 1$ & $\begin{array}{c}2.018^{* * *} \\
(3.31)\end{array}$ & $\begin{array}{c}2.028^{* * *} \\
(3.21)\end{array}$ \\
\hline $2007 \mathrm{H} 1 \times \mathrm{SHR}$ & $\begin{array}{l}1.247 \\
(1.37)\end{array}$ & $\begin{array}{c}0.448 \\
(0.45)\end{array}$ \\
\hline $2007 \mathrm{H} 1 \times \mathrm{HPE}$ & $\begin{array}{l}0.180 \\
(0.80)\end{array}$ & $\begin{array}{l}0.164 \\
(0.64)\end{array}$ \\
\hline $\mathrm{SHR} \times \mathrm{HPE} \times 2007 \mathrm{H} 1$ & $\begin{array}{l}-0.235 \\
(-0.72)\end{array}$ & $\begin{array}{l}-0.155 \\
(-0.42)\end{array}$ \\
\hline 2007H1 & $\begin{array}{l}-0.289 \\
(-0.48)\end{array}$ & $\begin{array}{c}0.098 \\
(0.15)\end{array}$ \\
\hline SHR & $\begin{array}{c}-1.632^{* * *} \\
(-4.68)\end{array}$ & $\begin{array}{c}-9.961 * * * \\
(-6.41)\end{array}$ \\
\hline HPE & $\begin{array}{l}-0.007 \\
(-0.09)\end{array}$ & \\
\hline $620^{-}$ & $\begin{array}{l}0.157 \\
(0.46)\end{array}$ & $\begin{array}{l}0.206 \\
(0.58)\end{array}$ \\
\hline $620^{-} \times \mathrm{SHR}$ & $\begin{array}{l}-0.210 \\
(-0.41)\end{array}$ & $\begin{array}{l}-0.281 \\
(-0.53)\end{array}$ \\
\hline $620^{-} \times \mathrm{HPE}$ & $\begin{array}{l}-0.117 \\
(-0.98)\end{array}$ & $\begin{array}{l}-0.129 \\
(-1.04)\end{array}$ \\
\hline $\mathrm{SHR} \times \mathrm{HPE}$ & $\begin{array}{l}0.073 \\
(0.65)\end{array}$ & $\begin{array}{l}-0.224 \\
(-0.42)\end{array}$ \\
\hline $620^{-} \times \mathrm{SHR} \times \mathrm{HPE}$ & $\begin{array}{l}0.193 \\
(1.09)\end{array}$ & $\begin{array}{l}0.213 \\
(1.15) \\
\end{array}$ \\
\hline MSA FE & No & Yes \\
\hline $\mathrm{R} 2$ & 0.105 & 0.231 \\
\hline $\mathrm{N}$ & 3704 & 3704 \\
\hline
\end{tabular}

The table reports the estimated coefficients of the following regression:

$\Delta 620_{k, i, t}=\alpha+\beta_{1} 620_{k}^{-} \times S H R_{i, t} \times 2007 H 1_{t}+\beta_{2} 620_{k}^{-} \times S H R_{i, t} \times H P E_{i} \times 2007 H 1_{t}+\beta_{3} 620_{k}^{-}+\beta_{4} S H R_{i, t}+\beta_{5} H P E_{i}+$ $\beta_{6} 2007 H 1_{t}+\beta_{7} 620_{k}^{-} \times S H R_{i, t}+\beta_{8} 620_{k}^{-} \times H P E_{i}+\beta_{9} S H R_{i, t} \times H P E_{i}+\beta_{10} S H R_{i, t} \times H P E_{i} \times 620_{k}^{-}+\beta_{11} 2007 H 1_{t} \times 620_{k}^{-}$

$+\beta_{12} 2007 H 1_{t} \times H P E_{i}+\beta_{13} 2007 H 1_{t} \times S H R_{i, t}+\beta_{14} 2007 H 1_{t} \times H P E_{i} \times 620_{k}^{-}+\beta_{15} 2007 H 1_{t} \times S H R_{i, t} \times H P E_{i}+\epsilon_{i, t}$

$\Delta 620_{k, i, t}$ is the annual growth in loans purchased by the GSEs of type $k 620^{-}$(FICO between 610-619) or 620 ${ }^{+}$(FICO between 620-629) in MSA $i$ at time $t$. $S H R_{i, t}$ is the GSEs' share of all outstanding mortgages in MSA $i$ at the beginning of time $t$. $H P E_{i}$ is the Saiz measure of elasticity in MSA $i$. $2007 H 1_{t}$ is an indicator that takes value 1 if $t$ equals the first half of 2007 . $620_{k}^{-}$is an indicator that takes value 1 if $k$ equals $620^{-}$and 0 otherwise. The panel data are semi-annual and span from 2005 to 2008. Standard errors are clustered at the MSA level and are analytically weighted. ***, **, and * indicate significance at the $1 \%, 5 \%$, and $10 \%$ level. T-statistics are shown in brackets. Sources: McDash and Saiz (2010). 


\section{Table 5: Passive Story and Change in High-Risk Acquisitions}

\begin{tabular}{|c|c|c|c|c|c|}
\hline & \multicolumn{5}{|c|}{$\Delta \mathrm{HRI}$} \\
\hline & $(1)$ & $(2)$ & (3) & (4) & (5) \\
\hline $\mathrm{SHR} \times 2007 \mathrm{H} 1$ & & $\begin{array}{c}0.383^{* * *} \\
(5.89)\end{array}$ & $\begin{array}{c}0.376^{* * *} \\
(4.69)\end{array}$ & $\begin{array}{c}0.359^{* * *} \\
(5.51)\end{array}$ & $\begin{array}{c}0.333^{* * *} \\
(4.10)\end{array}$ \\
\hline $\mathrm{SHR} \times \mathrm{HPE} \times 2007 \mathrm{H} 1$ & & $\begin{array}{c}-0.133^{* * *} \\
(-5.06)\end{array}$ & $\begin{array}{c}-0.146^{* * *} \\
(-4.35)\end{array}$ & $\begin{array}{c}-0.126^{* * *} \\
(-5.05)\end{array}$ & $\begin{array}{c}-0.141^{* * *} \\
(-4.30)\end{array}$ \\
\hline$\Delta$ PLEXIT $\times 2007 \mathrm{H} 1$ & $\begin{array}{l}0.095 \\
(1.14)\end{array}$ & $\begin{array}{c}0.023 \\
(0.30)\end{array}$ & $\begin{array}{l}0.030 \\
(0.33)\end{array}$ & $\begin{array}{l}0.570 \\
(1.19)\end{array}$ & $\begin{array}{l}0.235 \\
(0.35)\end{array}$ \\
\hline $\mathrm{SHR} \times \Delta \mathrm{PLEXIT} \times 2007 \mathrm{H} 1$ & & & & $\begin{array}{l}-0.896 \\
(-1.23)\end{array}$ & $\begin{array}{l}-0.344 \\
(-0.34)\end{array}$ \\
\hline $\mathrm{HPE} \times 2007 \mathrm{H} 1$ & & $\begin{array}{c}0.094^{* * *} \\
(5.43)\end{array}$ & $\begin{array}{c}0.107^{* * *} \\
(4.83)\end{array}$ & $\begin{array}{c}0.089^{* * *} \\
(5.39)\end{array}$ & $\begin{array}{c}0.103^{* * *} \\
(4.78)\end{array}$ \\
\hline 2007H1 & $\begin{array}{c}0.055^{* * *} \\
(6.93)\end{array}$ & $\begin{array}{c}-0.193 * * * \\
(-4.73)\end{array}$ & $\begin{array}{c}-0.203^{* * *} \\
(-4.02)\end{array}$ & $\begin{array}{c}-0.178^{* * *} \\
(-4.28)\end{array}$ & $\begin{array}{c}-0.175^{* * *} \\
(-3.40)\end{array}$ \\
\hline$\Delta$ PLEXIT & $\begin{array}{l}-0.030 \\
(-1.55)\end{array}$ & $\begin{array}{c}-0.033^{*} \\
(-1.72)\end{array}$ & $\begin{array}{l}-0.041 \\
(-1.36)\end{array}$ & $\begin{array}{c}-0.714^{* * *} \\
(-3.66)\end{array}$ & $\begin{array}{c}-0.596^{* * *} \\
(-2.89)\end{array}$ \\
\hline $\mathrm{SHR} \times \Delta \mathrm{PLEXIT}$ & & & & $\begin{array}{c}1.112^{* * *} \\
(3.54)\end{array}$ & $\begin{array}{c}0.904^{* * *} \\
(2.90)\end{array}$ \\
\hline$\Delta$ GSEOLD & $\begin{array}{c}-0.063^{* *} \\
(-2.40)\end{array}$ & $\begin{array}{l}-0.045 \\
(-1.53)\end{array}$ & $\begin{array}{l}0.036 \\
(0.93)\end{array}$ & $\begin{array}{l}-0.045 \\
(-1.54)\end{array}$ & $\begin{array}{l}0.035 \\
(0.91)\end{array}$ \\
\hline HPE & & $\begin{array}{c}-0.025^{* *} \\
(-2.55)\end{array}$ & & $\begin{array}{c}-0.021^{* *} \\
(-2.13)\end{array}$ & \\
\hline SHR & & $\begin{array}{c}-0.199 * * * \\
(-4.39)\end{array}$ & $\begin{array}{c}-0.771^{* * *} \\
(-4.40)\end{array}$ & $\begin{array}{c}-0.188^{* * *} \\
(-4.30)\end{array}$ & $\begin{array}{c}-0.741^{* * *} \\
(-4.35)\end{array}$ \\
\hline $\mathrm{SHR} \times \mathrm{HPE}$ & & $\begin{array}{c}0.039 * * \\
(2.52)\end{array}$ & $\begin{array}{l}-0.082 \\
(-1.25)\end{array}$ & $\begin{array}{c}0.033^{* *} \\
(2.14)\end{array}$ & $\begin{array}{l}-0.097 \\
(-1.50)\end{array}$ \\
\hline MSA FE & No & No & Yes & No & Yes \\
\hline $\mathrm{R} 2$ & 0.158 & 0.197 & 0.331 & 0.203 & 0.336 \\
\hline $\mathrm{N}$ & 2179 & 1861 & 1861 & 1861 & 1861 \\
\hline
\end{tabular}

The table reports the estimated coefficients of the following regression:

$$
\begin{aligned}
\Delta \mathrm{HRI}_{i, t} & =\alpha+\beta_{1} \Delta G S E O L D_{i, t}+\beta_{2} \Delta P L E X I T_{i, t}+\beta_{3} 2007 H 1_{t}+\beta_{4} 2007 H 1_{t} \times \Delta P L E X I T_{i, t}+\beta_{5} S H R_{i, t}+\beta_{6} H P E_{i} \\
& +\beta_{7} S H R_{i, t} \times H P E_{i}+\beta_{8} S H R_{i, t} \times \Delta P L E X I T_{i, t}+\beta_{9} 2007 H 1_{t} \times S H R_{i, t} \times \Delta P L E X I T_{i, t}+\beta_{10} 2007 H 1_{t} \times H P E_{i, t} \\
& +\beta_{11} 2007 H 1_{t} \times S H R_{i, t}+\beta_{12} 2007 H 1_{t} \times S H R_{i, t} \times H P E_{i, t}+\epsilon_{i, t}
\end{aligned}
$$

$\Delta \mathrm{HRI}_{i, t}$ is the change in the proportion of mortgages purchased by the GSEs that had LTV>80 in MSA $i$ at time $t$. $\triangle G S E O L D_{i, t}$ is the first difference of GSE high-LTV loans purchases in period $t-1$ weighted by total GSE purchases in period $t$ in MSA $i . \triangle P L E X I T_{i, t}$ is the first difference of the change in private-label high LTV purchases between period $t$ and $t-1$ weighted by total GSE purchases in period $t . S H R_{i, t}$ is the GSEs' share of all outstanding mortgages in MSA $i$ at the beginning of time $t . H P E_{i}$ is the Saiz measure of elasticity in MSA $i .2007 H 1_{t}$ is an indicator that takes value 1 if $t$ equals the first half of 2007. The panel data are semi-annual and span from 2005 to 2008. Standard errors are clustered at the MSA level and are analytically weighted. ${ }^{* *},{ }^{* *}$, and $*$ indicate significance at the $1 \%, 5 \%$, and $10 \%$ level. T-statistics are shown in brackets. Sources: McDash and Saiz (2010). 
Table 6: Passive Story and Growth in Loans around FICO of 620 - Panel A

\begin{tabular}{|c|c|c|c|c|c|}
\hline & \multicolumn{5}{|c|}{$\Delta 620^{-}$} \\
\hline & $(1)$ & $(2)$ & (3) & (4) & (5) \\
\hline $2007 \mathrm{H} 1 \times \mathrm{SHR}$ & & $\begin{array}{c}8.201^{* * *} \\
(3.61)\end{array}$ & $\begin{array}{c}7.637^{* * *} \\
(3.35)\end{array}$ & $\begin{array}{c}12.034^{* * *} \\
(4.05)\end{array}$ & $\begin{array}{c}11.952^{* * *} \\
(3.75)\end{array}$ \\
\hline $\mathrm{SHR} \times \mathrm{HPE} \times 2007 \mathrm{H} 1$ & & $\begin{array}{c}-3.152^{* * *} \\
(-4.23)\end{array}$ & $\begin{array}{c}-3.172^{* * *} \\
(-4.25)\end{array}$ & $\begin{array}{c}-2.981^{* * *} \\
(-3.92)\end{array}$ & $\begin{array}{c}-2.977^{* * *} \\
(-3.87)\end{array}$ \\
\hline$\Delta \mathrm{PLEXIT} \times 2007 \mathrm{H} 1$ & $\begin{array}{l}-0.300 \\
(-0.98)\end{array}$ & $\begin{array}{l}-0.413 \\
(-1.38)\end{array}$ & $\begin{array}{l}-0.365 \\
(-1.17)\end{array}$ & $\begin{array}{r}4.077^{*} \\
(1.83)\end{array}$ & $\begin{array}{c}4.759^{*} \\
(1.93)\end{array}$ \\
\hline $\mathrm{SHR} \times \Delta \mathrm{PLEXIT} \times 2007 \mathrm{H} 1$ & & & & $\begin{array}{c}-6.632^{* *} \\
(-2.02)\end{array}$ & $\begin{array}{c}-7.572^{* *} \\
(-2.07)\end{array}$ \\
\hline $\mathrm{HPE} \times 2007 \mathrm{H} 1$ & & $\begin{array}{c}2.140^{* * *} \\
(4.07)\end{array}$ & $\begin{array}{c}2.181^{* * *} \\
(4.15)\end{array}$ & $\begin{array}{c}2.027^{* * *} \\
(3.78)\end{array}$ & $\begin{array}{c}2.053^{* * *} \\
(3.79)\end{array}$ \\
\hline 2007H1 & $\begin{array}{c}0.974^{* * *} \\
(5.15)\end{array}$ & $\begin{array}{c}-4.451^{* * *} \\
(-2.92)\end{array}$ & $\begin{array}{c}-4.250^{* * *} \\
(-2.80)\end{array}$ & $\begin{array}{c}-7.047^{* * *} \\
(-3.56)\end{array}$ & $\begin{array}{c}-7.174^{* * *} \\
(-3.39)\end{array}$ \\
\hline$\Delta$ PLEXIT & $\begin{array}{c}-0.122^{* * *} \\
(-7.23)\end{array}$ & $\begin{array}{c}-0.128^{* * *} \\
(-6.76)\end{array}$ & $\begin{array}{c}-0.107^{* * *} \\
(-5.69)\end{array}$ & $\begin{array}{l}-0.032 \\
(-0.26)\end{array}$ & $\begin{array}{l}-0.036 \\
(-0.26)\end{array}$ \\
\hline SHR $\times \Delta$ PLEXIT & & & & $\begin{array}{l}-0.158 \\
(-0.79)\end{array}$ & $\begin{array}{l}-0.117 \\
(-0.51)\end{array}$ \\
\hline$\Delta$ GSEOLD & $\begin{array}{c}0.125^{* * * *} \\
(5.30)\end{array}$ & $\begin{array}{c}0.124^{* * * *} \\
(4.65)\end{array}$ & $\begin{array}{l}0.040 \\
(1.53)\end{array}$ & $\begin{array}{c}0.123^{* * *} \\
(4.53)\end{array}$ & $\begin{array}{l}0.039 \\
(1.47)\end{array}$ \\
\hline HPE & & $\begin{array}{l}-0.164 \\
(-1.08)\end{array}$ & & $\begin{array}{l}-0.164 \\
(-1.08)\end{array}$ & \\
\hline SHR & & $\begin{array}{c}-1.543^{* *} \\
(-2.49)\end{array}$ & $\begin{array}{c}-8.540 * * * \\
(-3.92)\end{array}$ & $\begin{array}{c}-1.574^{* *} \\
(-2.54)\end{array}$ & $\begin{array}{c}-8.477^{* * * *} \\
(-3.87)\end{array}$ \\
\hline $\mathrm{SHR} \times \mathrm{HPE}$ & & $\begin{array}{l}0.340 \\
(1.52)\end{array}$ & $\begin{array}{l}0.207 \\
(0.26)\end{array}$ & $\begin{array}{l}0.340 \\
(1.53)\end{array}$ & $\begin{array}{c}0.184 \\
(0.23)\end{array}$ \\
\hline MSA FE & No & No & Yes & No & Yes \\
\hline $\mathrm{R} 2$ & 0.120 & 0.193 & 0.307 & 0.196 & 0.311 \\
\hline $\mathrm{N}$ & 2009 & 1731 & 1731 & 1731 & 1731 \\
\hline
\end{tabular}

Panel A of the table reports the estimated coefficients of the following regression:

$$
\begin{aligned}
\Delta 620_{i, t}^{-} & =\alpha+\beta_{1} \Delta G S E O L D_{i, t}+\beta_{2} \Delta P L E X I T_{i, t}+\beta_{3} 2007 H 1_{t}+\beta_{4} 2007 H 1_{t} \times \Delta P L E X I T_{i, t}+\beta_{5} S H R_{i, t}+\beta_{6} H P E_{i} \\
& +\beta_{7} S H R_{i, t} \times H P E_{i}+\beta_{8} S H R_{i, t} \times \Delta P L E X I T_{i, t}+\beta_{9} 2007 H 1_{t} \times S H R_{i, t} \times \Delta P L E X I T_{i, t}+\beta_{10} 2007 H 1_{t} \times H P E_{i, t} \\
& +\beta_{11} 2007 H 1_{t} \times S H R_{i, t}+\beta_{12} 2007 H 1_{t} \times S H R_{i, t} \times H P E_{i, t}+\epsilon_{i, t}
\end{aligned}
$$

$\Delta 620_{i, t}^{-}$is the annual growth in loans purchased by the GSEs that are 620- (FICO between 610 and 619) in MSA $i$ at time $t$. $\triangle G S E O L D_{i, t}$ is the annual one-period lagged growth of GSE aquisitions of $620^{-}$loans in MSA $i$ at time $t . \triangle P L E X I T_{i, t}$ is the decrease in private-label purchases of $620^{-}$loans in NSA $i$ at time $t . S H R_{i, t}$ is the GSEs' share of all outstanding mortgages in MSA $i$ at the beginning of time $t . H P E_{i}$ is the Saiz measure of elasticity in MSA $i .2007 H 1_{t}$ is an indicator that takes value 1 if $t$ equals the first half of 2007. The panel data are semi-annual and span from 2005 to 2008. Standard errors are clustered at the MSA level and are analytically weighted. ${ }^{* * *},{ }^{* *}$, and $*$ indicate significance at the $1 \%, 5 \%$, and $10 \%$ level. T-statistics are shown in brackets. Sources: McDash and Saiz (2010). 
Table 6: Passive Story and Growth in Loans around FICO of 620 - Panel B

\begin{tabular}{|c|c|c|c|c|c|}
\hline & \multicolumn{5}{|c|}{$\Delta 620^{+}$} \\
\hline & $(1)$ & $(2)$ & $(3)$ & $(4)$ & $(5)$ \\
\hline $2007 \mathrm{H} 1 \times \mathrm{SHR}$ & & $\begin{array}{l}0.443 \\
(0.46)\end{array}$ & $\begin{array}{l}0.016 \\
(0.02)\end{array}$ & $\begin{array}{l}0.297 \\
(0.21)\end{array}$ & $\begin{array}{l}-0.545 \\
(-0.32)\end{array}$ \\
\hline $\mathrm{SHR} \times \mathrm{HPE} \times 2007 \mathrm{H} 1$ & & $\begin{array}{l}-0.064 \\
(-0.18)\end{array}$ & $\begin{array}{l}-0.062 \\
(-0.15)\end{array}$ & $\begin{array}{l}-0.080 \\
(-0.22)\end{array}$ & $\begin{array}{l}-0.068 \\
(-0.17)\end{array}$ \\
\hline$\Delta$ PLEXIT $\times 2007 \mathrm{H} 1$ & $\begin{array}{l}0.187 \\
(1.17)\end{array}$ & $\begin{array}{l}0.270 \\
(1.19)\end{array}$ & $\begin{array}{l}0.329 \\
(1.15)\end{array}$ & $\begin{array}{l}0.396 \\
(0.33)\end{array}$ & $\begin{array}{l}-0.085 \\
(-0.06)\end{array}$ \\
\hline $\mathrm{SHR} \times \Delta \mathrm{PLEXIT} \times 2007 \mathrm{H} 1$ & & & & $\begin{array}{l}-0.195 \\
(-0.11)\end{array}$ & $\begin{array}{l}0.637 \\
(0.29)\end{array}$ \\
\hline $\mathrm{HPE} \times 2007 \mathrm{H} 1$ & & $\begin{array}{l}0.058 \\
(0.23)\end{array}$ & $\begin{array}{l}0.086 \\
(0.31)\end{array}$ & $\begin{array}{l}0.070 \\
(0.28)\end{array}$ & $\begin{array}{l}0.089 \\
(0.32)\end{array}$ \\
\hline 2007H1 & $\begin{array}{c}0.557^{* * *} \\
(5.16)\end{array}$ & $\begin{array}{l}0.193 \\
(0.29)\end{array}$ & $\begin{array}{l}0.316 \\
(0.42)\end{array}$ & $\begin{array}{c}0.290 \\
(0.30)\end{array}$ & $\begin{array}{l}0.687 \\
(0.59)\end{array}$ \\
\hline$\Delta$ PLEXIT & $\begin{array}{c}-0.172^{* * *} \\
(-7.77)\end{array}$ & $\begin{array}{c}-0.173^{* * *} \\
(-7.01)\end{array}$ & $\begin{array}{c}-0.155^{* * *} \\
(-6.23)\end{array}$ & $\begin{array}{c}-0.452^{* *} \\
(-2.19)\end{array}$ & $\begin{array}{c}-0.389 * \\
(-1.79)\end{array}$ \\
\hline $\mathrm{SHR} \times \Delta \mathrm{PLEXIT}$ & & & & $\begin{array}{l}0.433 \\
(1.38)\end{array}$ & $\begin{array}{l}0.362 \\
(1.09)\end{array}$ \\
\hline$\Delta$ GSEOLD & $\begin{array}{c}0.221^{* * * *} \\
(11.99)\end{array}$ & $\begin{array}{c}0.221 * * * \\
(11.55)\end{array}$ & $\begin{array}{c}0.150^{* * * *} \\
\quad(6.25)\end{array}$ & $\begin{array}{c}0.225^{* * *} \\
(11.49)\end{array}$ & $\begin{array}{c}0.155^{* * *} \\
(6.28)\end{array}$ \\
\hline HPE & & $\begin{array}{l}0.020 \\
(0.32)\end{array}$ & & $\begin{array}{l}0.004 \\
(0.07)\end{array}$ & \\
\hline SHR & & $\begin{array}{c}-1.179 * * * \\
(-4.16)\end{array}$ & $\begin{array}{c}-9.433^{* * *} \\
(-6.70)\end{array}$ & $\begin{array}{c}-1.173^{* * *} \\
(-4.25)\end{array}$ & $\begin{array}{c}-9.507 * * * \\
(-6.69)\end{array}$ \\
\hline $\mathrm{SHR} \times \mathrm{HPE}$ & & $\begin{array}{l}0.040 \\
(0.40)\end{array}$ & $\begin{array}{l}0.246 \\
(0.46)\end{array}$ & $\begin{array}{l}0.062 \\
(0.63)\end{array}$ & $\begin{array}{l}0.303 \\
(0.58)\end{array}$ \\
\hline MSA FE & No & No & Yes & No & Yes \\
\hline $\mathrm{R} 2$ & 0.191 & 0.225 & 0.344 & 0.230 & 0.347 \\
\hline $\mathrm{N}$ & 2071 & 1782 & 1782 & 1782 & 1782 \\
\hline
\end{tabular}

Panel B of the table reports the estimated coefficients of the following regression:

$$
\begin{aligned}
\Delta 620_{i, t}^{+} & =\alpha+\beta_{1} \Delta G S E O L D_{i, t}+\beta_{2} \Delta P L E X I T_{i, t}+\beta_{3} 2007 H 1_{t}+\beta_{4} 2007 H 1_{t} \times \Delta P L E X I T_{i, t}+\beta_{5} S H R_{i, t}+\beta_{6} H P E_{i} \\
& +\beta_{7} S H R_{i, t} \times H P E_{i}+\beta_{8} S H R_{i, t} \times \Delta P L E X I T_{i, t}+\beta_{9} 2007 H 1_{t} \times S H R_{i, t} \times \Delta P L E X I T_{i, t}+\beta_{10} 2007 H 1_{t} \times H P E_{i, t} \\
& +\beta_{11} 2007 H 1_{t} \times S H R_{i, t}+\beta_{12} 2007 H 1_{t} \times S H R_{i, t} \times H P E_{i, t}+\epsilon_{i, t}
\end{aligned}
$$

$\Delta 620_{i, t}^{+}$is the annual growth in loans purchased by the GSEs that are $620^{+}$(FICO between 620 and 629) in MSA $i$ at time $t$. $\triangle G S E O L D_{i, t}$ is the annual one-period lagged growth of GSE aquisitions of $620^{+}$loans in MSA $i$ at time $t . \Delta P L E X I T_{i, t}$ is the decrease in private-label purchases of $620^{+}$loans in NSA $i$ at time $t$. $S H R_{i, t}$ is the GSEs' share of all outstanding mortgages in MSA $i$ at the beginning of time $t . H P E_{i}$ is the Saiz measure of elasticity in MSA $i .2007 H 1_{t}$ is an indicator that takes value 1 if $t$ equals the first half of 2007. The panel data are semi-annual and span from 2005 to 2008. Standard errors are clustered at the MSA level and are analytically weighted. ***, **, and * indicate significance at the 1\%, 5\%, and 10\% level. T-statistics are shown in brackets. Sources: McDash and Saiz (2010). 
Table 7: Portfolio Lending (Falsification)

\begin{tabular}{lcc}
\hline \hline & & $\Delta$ HRI \\
\cline { 2 - 3 } & $(1)$ & $(2)$ \\
\hline SHR $\times 2007 \mathrm{H} 1$ & 0.022 & 0.026 \\
& $(0.20)$ & $(0.23)$ \\
$\mathrm{SHR} \times \mathrm{HPE} \times 2007 \mathrm{H} 1$ & -0.004 & -0.005 \\
& $(-0.14)$ & $(-0.16)$ \\
$\mathrm{HPE} \times 2007 \mathrm{H} 1$ & 0.004 & 0.005 \\
& $(0.21)$ & $(0.23)$ \\
$2007 \mathrm{H} 1$ & -0.011 & -0.016 \\
& $(-0.17)$ & $(-0.21)$ \\
$\mathrm{SHR}$ & $-0.118^{* * *}$ & $-0.406^{* * *}$ \\
$\mathrm{HPE}$ & $(-3.06)$ & $(-3.38)$ \\
$\mathrm{SHR} \times \mathrm{HPE}$ & $-0.018^{* *}$ & $(2.40)$ \\
\hline $\mathrm{MSA}$ FE & $(-2.45)$ & Yes \\
$\mathrm{R} 2$ & $0.026^{* *}$ & 0.033 \\
$\mathrm{~N}$ & $(2.24)$ & 1861 \\
\hline \hline
\end{tabular}

The table reports the estimated coefficients of the following regression:

$$
\begin{aligned}
\Delta \mathrm{HRI}_{i, t} & =\alpha+\beta_{1} S H R_{i, t}+\beta_{2} H P E_{i}+\beta_{3} 2007 H 1_{t}+\beta_{4} S H R_{i, t} \times H P E_{i}+\beta_{5} 2007 H 1 \times H P E_{i} \\
& +\beta_{6} 2007 H 1 \times S H R_{i, t}+\beta_{7} 2007 H 1 \times S H R_{i, t} \times H P E_{i}+\epsilon_{i, t}
\end{aligned}
$$

$\Delta \mathrm{HRI}_{i, t}$ is the change in the proportion of mortgages that had LTV $>80$ at origination and that were held on portfolio by lenders in MSA $i$ at time $t . S H R_{i, t}$ is the GSEs' share of all outstanding mortgages in MSA $i$ at the beginning of time $t$. $H P E_{i}$ is the Saiz measure of elasticity in MSA $i .2007 H 1_{t}$ is an indicator that takes value 1 if $t$ equals the first half of 2007. The panel data are semi-annual and span from 2005 to 2008 . ***,**, and * indicate significance at the 1\%, 5\%, and 10\% level. T-statistics are shown in brackets. Sources: McDash and Saiz (2010). 


\section{Table 8: Growth in Agency Goals (Alternative Hypothesis)}

\begin{tabular}{|c|c|c|c|c|}
\hline & \multicolumn{4}{|c|}{$\Delta \mathrm{HRI}$} \\
\hline & $(1)$ & $(2)$ & $(3)$ & $(4)$ \\
\hline$\Delta$ GOALS & $\begin{array}{c}0.027^{* * *} \\
(2.63)\end{array}$ & $\begin{array}{l}0.021 \\
(1.05)\end{array}$ & & \\
\hline$\Delta$ ADJ GOALS & & & $\begin{array}{c}0.032^{* * *} \\
(4.69)\end{array}$ & $\begin{array}{c}0.035^{* * *} \\
(2.81)\end{array}$ \\
\hline 2007H1 & $\begin{array}{c}0.060^{* * *} \\
(5.65)\end{array}$ & $\begin{array}{c}0.062^{* * *} \\
(4.33)\end{array}$ & $\begin{array}{c}0.058^{* * *} \\
(5.78)\end{array}$ & $\begin{array}{c}0.060^{* * *} \\
(4.57)\end{array}$ \\
\hline$\Delta$ GOALS $\times 2007 \mathrm{H} 1$ & $\begin{array}{l}-0.054 \\
(-1.55)\end{array}$ & $\begin{array}{l}-0.056 \\
(-0.98)\end{array}$ & & \\
\hline$\Delta$ ADJ GOALS $\times 2007 \mathrm{H} 1$ & & & $\begin{array}{c}-0.051^{* * *} \\
(-2.65)\end{array}$ & $\begin{array}{c}-0.060 * \\
(-1.84)\end{array}$ \\
\hline MSA FE & No & Yes & No & Yes \\
\hline $\mathrm{R} 2$ & 0.278 & 0.478 & 0.288 & 0.489 \\
\hline $\mathrm{N}$ & 815 & 815 & 815 & 815 \\
\hline
\end{tabular}

The table reports the estimated coefficients of the following regression:

$$
\Delta \mathrm{HRI}_{i, t}=\alpha+\beta_{1} \Delta z_{i, t}+\beta_{2} 2007 H 1_{t}+\beta_{3} 2007 H 1 \times \Delta z_{i, t}+\epsilon_{i, t}
$$

$\Delta \mathrm{HRI}_{i, t}$ is the change in the proportion of mortgages purchased by the GSEs that had LTV>80 at origination in MSA $i$ at time $t . x_{i, t}$ is (1) the growth in the number of goals eligible towards the GSEs' goals in columns 1 and 2, and (2) the number of goals eligible towards the GSEs' goals multiplied by how much the average loan in MSA $i$ counted towards the GSEs' goals in columns 3 and 4. $2007 H 1_{t}$ is an indicator that takes value 1 if $t$ equals the first half of 2007 . The panel data are annual and span from 2005 to 2008. Standard errors are clustered at the MSA level and are analytically weighted. ***, **, and * indicate significance at the $1 \%, 5 \%$, and $10 \%$ level. T-statistics are shown in brackets. Sources: McDash and HMDA. 


\section{Table 9: Fannie Mae and Freddie Mac — Panel A (Robustness)}

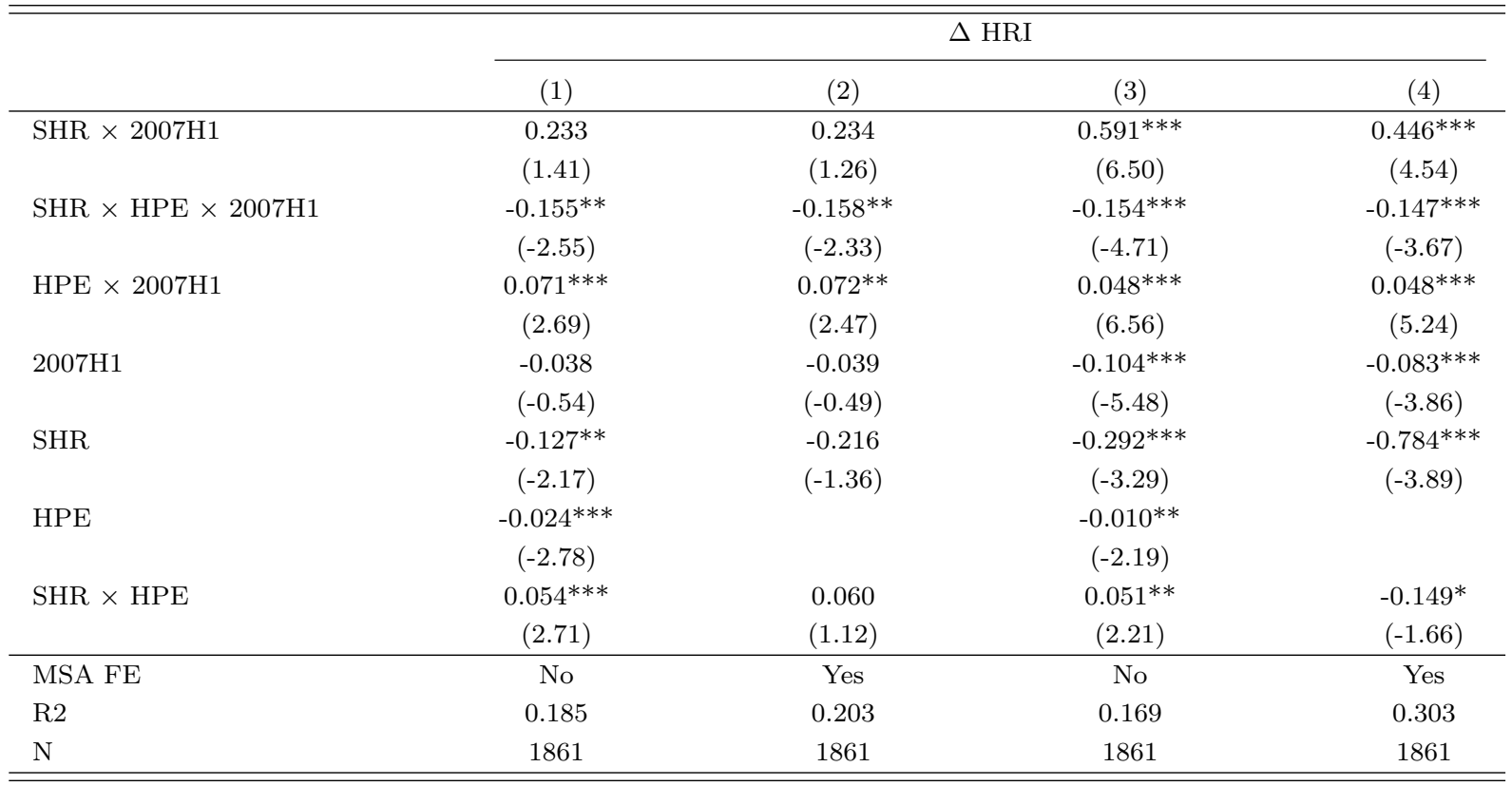

The table reports the estimated coefficients of the following regression:

$$
\begin{aligned}
\Delta \mathrm{HRI}_{i, t} & =\alpha+\beta_{1} S H R_{i, t}+\beta_{2} H P E_{i}+\beta_{3} 2007 H 1_{t}+\beta_{4} S H R_{i, t} \times H P E_{i}+\beta_{5} 2007 H 1 \times H P E_{i}+\beta_{6} 2007 H 1 \times S H R_{i, t} \\
& +\beta_{7} 2007 H 1 \times S H R_{i, t} \times H P E_{i}+\epsilon_{i, t}
\end{aligned}
$$

$\Delta \mathrm{HRI}_{i, t}$ is the change in the proportion of mortgages purchased by Fannie Mae (columns 1 and 2) and Freddie Mac (columns 3 and 4) that had LTV > 80 at origination in MSA $i$ at time $t . S H R_{i, t}$ is Fannie Mae's (Panel A: columns 1, 2; Panel B: columns 3, 4) and Freddie Mac's (Panel A: columns 3, 4 Panel B: columns 1, 2) share of all outstanding mortgages in MSA $i$ at the beginning of time $t . H P E_{i}$ is the Saiz measure of elasticity in MSA $i .2007 H 1_{t}$ is an indicator that takes value 1 if $t$ equals the first half of 2007. The panel data are semi-annual and span from 2005 to 2008. Standard errors are clustered at the MSA level and are analytically weighted. ${ }^{* *},{ }^{* *}$, and $*$ indicate significance at the $1 \%, 5 \%$, and $10 \%$ level. T-statistics are shown in brackets. Sources: McDash and Saiz (2010). 
Table 9: Fannie Mae and Freddie Mac — Panel B (Falsification)

\begin{tabular}{|c|c|c|c|c|}
\hline & \multicolumn{4}{|c|}{$\Delta \mathrm{HRI}$} \\
\hline & (1) & $(2)$ & (3) & (4) \\
\hline \multirow[t]{2}{*}{ SHR $\times 2007 \mathrm{H} 1$} & $0.303^{*}$ & 0.116 & 0.152 & 0.164 \\
\hline & $(1.89)$ & $(0.73)$ & $(1.01)$ & (1.03) \\
\hline \multirow[t]{2}{*}{$\mathrm{SHR} \times \mathrm{HPE} \times 2007 \mathrm{H} 1$} & $-0.079 *$ & -0.057 & -0.051 & -0.051 \\
\hline & $(-1.73)$ & $(-1.26)$ & $(-1.16)$ & $(-1.10)$ \\
\hline \multirow[t]{2}{*}{$\mathrm{HPE} \times 2007 \mathrm{H} 1$} & $0.022^{* *}$ & $0.018^{*}$ & 0.028 & 0.028 \\
\hline & $(2.02)$ & $(1.75)$ & $(1.55)$ & $(1.45)$ \\
\hline \multirow[t]{2}{*}{ 2007H1 } & -0.011 & 0.019 & -0.016 & -0.021 \\
\hline & $(-0.28)$ & $(0.51)$ & $(-0.26)$ & $(-0.32)$ \\
\hline \multirow[t]{2}{*}{ SHR } & $-0.227^{* * *}$ & $-1.101^{* * *}$ & -0.003 & 0.025 \\
\hline & $(-4.31)$ & $(-8.59)$ & $(-0.06)$ & $(0.20)$ \\
\hline \multirow[t]{2}{*}{ HPE } & $-0.011^{* * *}$ & & -0.006 & \\
\hline & $(-3.11)$ & & $(-1.02)$ & \\
\hline \multirow[t]{2}{*}{$\mathrm{SHR} \times \mathrm{HPE}$} & $0.041^{* * *}$ & 0.041 & 0.013 & 0.031 \\
\hline & $(2.71)$ & $(1.00)$ & $(0.86)$ & $(0.81)$ \\
\hline MSA FE & No & Yes & No & Yes \\
\hline $\mathrm{R} 2$ & 0.144 & 0.286 & 0.114 & 0.138 \\
\hline $\mathrm{N}$ & 1861 & 1861 & 1861 & 1861 \\
\hline
\end{tabular}

The table reports the estimated coefficients of the following regression:

$$
\begin{aligned}
\Delta \mathrm{HRI}_{i, t} & =\alpha+\beta_{1} S H R_{i, t}+\beta_{2} H P E_{i}+\beta_{3} 2007 H 1_{t}+\beta_{4} S H R_{i, t} \times H P E_{i}+\beta_{5} 2007 H 1 \times H P E_{i}+\beta_{6} 2007 H 1 \times S H R_{i, t} \\
& +\beta_{7} 2007 H 1 \times S H R_{i, t} \times H P E_{i}+\epsilon_{i, t}
\end{aligned}
$$

$\Delta \mathrm{HRI}_{i, t}$ is the change in the proportion of mortgages purchased by Fannie Mae (columns 1 and 2) and Freddie Mac (columns 3 and 4) that had LTV > 80 at origination in MSA $i$ at time $t . S H R_{i, t}$ is Fannie Mae's (Panel A: columns 1, 2; Panel B: columns 3, 4) and Freddie Mac's (Panel A: columns 3, 4 Panel B: columns 1, 2) share of all outstanding mortgages in MSA $i$ at the beginning of time $t . H P E_{i}$ is the Saiz measure of elasticity in MSA $i .2007 H 1_{t}$ is an indicator that takes value 1 if $t$ equals the first half of 2007. The panel data are semi-annual and span from 2005 to 2008. Standard errors are clustered at the MSA level and are analytically weighted. ${ }^{* * *}, * *$, and $*$ indicate significance at the $1 \%, 5 \%$, and $10 \%$ level. T-statistics are shown in brackets. Sources: McDash and Saiz (2010). 